\title{
Targeting metabolic flexibility by simultaneously inhibiting respiratory complex $I$ and lactate generation retards melanoma progression
}

\author{
Balkrishna Chaube ${ }^{1}$, Parmanand Malvi ${ }^{1}$, Shivendra Vikram Singh ${ }^{1}$, Naoshad \\ Mohammad $^{1}$, Avtar Singh Meena ${ }^{1,2}$ and Manoj Kumar Bhat ${ }^{1}$ \\ ${ }^{1}$ National Centre for Cell Science, Savitribai Phule Pune University Campus, Ganeshkhind, Pune, India \\ ${ }^{2}$ Current address: Department of Physiology, University of Tennessee Health Science Center, Memphis, USA \\ Correspondence to: Manoj Kumar Bhat, email: manojkbhat@nccs.res.in \\ Keywords: melanoma; complex I; LDH; metabolic catastrophe; synthetic lethality \\ Received: June 16,2015 Accepted: September 23, $2015 \quad$ Published: October 15, 2015
}

This is an open-access article distributed under the terms of the Creative Commons Attribution License, which permits unrestricted use, distribution, and reproduction in any medium, provided the original author and source are credited.

\section{ABSTRACT}

Melanoma is a largely incurable skin malignancy owing to the underlying molecular and metabolic heterogeneity confounded by the development of resistance. Cancer cells have metabolic flexibility in choosing either oxidative phosphorylation (OXPHOS) or glycolysis for ATP generation depending upon the nutrient availability in tumor microenvironment. In this study, we investigated the involvement of respiratory complex I and lactate dehydrogenase (LDH) in melanoma progression. We show that inhibition of complex I by metformin promotes melanoma growth in mice via elevating lactate and VEGF levels. In contrast, it leads to the growth arrest in vitro because of enhanced extracellular acidification as a result of increased glycolysis. Inhibition of LDH or lactate generation causes decrease in glycolysis with concomitant growth arrest both in vitro and in vivo. Blocking lactate generation in metformin-treated melanoma cells results in diminished cell proliferation and tumor progression in mice. Interestingly, inhibition of either LDH or complex I alone does not induce apoptosis, whereas inhibiting both together causes depletion in cellular ATP pool resulting in metabolic catastrophe induced apoptosis. Overall, our study suggests that LDH and complex I play distinct roles in regulating glycolysis and cell proliferation. Inhibition of these two augments synthetic lethality in melanoma.

\section{INTRODUCTION}

Malignant melanoma is one of the most aggressive forms of skin cancer with high metastatic potential and resistance to many cytotoxic agents $[1,2]$. Despite extensive research and partial successes gained by the use of currently available drugs there is no effective treatment against malignant melanoma [1-3]. Melanoma cases are increasing every year and account for about $75 \%$ of skin cancer-related deaths worldwide [2, 3]. Poor response to currently available therapeutic options and development of resistance to therapy warrant exploration of new strategies to treat melanoma.

Enhanced aerobic glycolysis is a characteristic feature of many cancers [3-5]. It has been reported that melanoma cells, owing to the BRAF mutation, depend majorly on glycolysis for ATP generation, and exhibit dysfunctional oxidative phosphorylation $[6,7]$. Cancer cells derive ATP, biosynthetic intermediates, and reducing equivalents by unusually engaging in biochemical pathways such as glycolysis, glutaminolysis, and the pentose phosphate pathway [5]. Normal (non-cancerous) cells derive ATP primarily through mitochondrial OXPHOS; while cancer cells rely mainly on aerobic glycolysis to generate ATP and glycolytic intermediates those facilitate rapid growth $[4,5]$. Enhanced lactate generation has been correlated with aggressiveness of cancer. Numerous studies have identified lactate dehydrogenase (LDH), which catalyzes the conversion of pyruvate to lactate, as the most consistent marker of the aggressive and rapidly growing cancers [8-11]. LDH plays 
an important role in regulating glycolysis, maintaining cellular redox state, mitochondrial physiology and tumor maintenance [12]. Altered metabolism of cancer cell can be associated with mitochondrial dysfunction which involves inhibition of OXPHOS, increase in reactive oxygen species (ROS) and promoting uncontrolled growth, that in turn further supports the development of a metastatic phenotype $[13,14]$. Respiratory complex I is the largest and most complex enzyme which catalyzes oxidation of NADH in electron transport chain [15]. Complex I plays important role in ATP generation in normal cells and is a main site of ROS generation, however, its role in tumorigenesis is largely unclear. Most of the reports suggest that complex I activity is suppressed in cancer cells and its inhibition promotes proliferation and metastasis [16-18]. Conversely, it has also been reported that melanoma cells display increased OXPHOS function which causes drug resistance [19-21]. Owing to the metabolic flexibility in choosing various metabolic pathways, particularly glutamine metabolism [22], melanoma cells can escape from perturbation of a molecule in a metabolic pathway [23]. Therefore, more than one molecules of different metabolic pathways need to be targeted for an effective and curative outcome.

Biguanides like metformin and phenformin are known to inhibit respiratory complex I. Metformin, a first line therapy for patients with type 2 diabetes mellitus (T2DM), is a member of the biguanides and has been recently discovered to have anti-tumorigenic activity [24, 25]. At physiological level, metformin exerts its biological activity by decreasing hepatic glucogenesis, increasing insulin sensitivity, elevating peripheral glucose uptake and reducing absorption of glucose from the gastrointestinal tract [26]. At the cellular level, metformin works primarily by inhibiting mitochondrial complex I, which impedes oxidative phosphorylation resulting in decreased ATP level leading to activation of AMPK [27-30]. Moreover, it has been shown that metformin decreases mitochondrial respiration coupled with ATP generation, thereby causing an increase in glycolysis $[31,32]$. The anticancer action of metformin has been shown in various cancers with distinct mechanisms [33, 34]. However, role of metformin in melanoma is not much clear. Unlike other cancer types, metformin is shown to have both tumor promoting as well as antitumor activity in melanoma [35-37]. Also, metformin, in combination with BRAF inhibitors, has been shown to suppress melanoma growth [38].

In the present study, with the speculation that disrupting ATP generating routes by inhibiting complex I and LDH together could be synthetically lethal to melanoma cells, we used metformin or phenformin and oxamate/dichloro acetate (DCA) to inhibit these two enzymes using both cell and animal models. We demonstrate that inhibition of complex I and LDH activity have distinct impact on cell growth and proliferation. Interestingly, inhibition of complex I by metformin further promotes aerobic glycolysis resulting in enhanced tumor growth in mice. Ablation of metformin-induced lactate generation by using oxamate or DCA leads to cytostasis and/or apoptosis in melanoma cells.

\section{RESULTS}

\section{Metformin exhibits distinct in vitro and in vivo actions on growth of melanoma}

Metformin suppresses tumor growth by inhibiting complex I which is influenced by glucose [30]. Moreover, glucose is known to alter the activity of respiratory enzymes [39]. Therefore, to explore the consequence(s) of complex I inhibition and influence of glucose on action of metformin on melanoma progression, we monitored isograft/xenograft progression in streptozotocin (STZ) induced hyperglycemic mice. We noted that metformin promoted B16F10 derived isograft progression in hyperglycemic mice as compared to untreated control (Figure 1A, 1B and 1C). Also, metformin positively influenced progression of tumor in normoglycemic C57BL/6J mice (Figure 1D, 1E and 1F). Similarly, oral administration of metformin promoted growth of A375 xenograft in hyperglycemic as well as in normoglycemic NOD/SCID mice as compared to untreated control (Figure $1 \mathrm{G}, 1 \mathrm{H}$ and $1 \mathrm{I})$.

To check the cellular and molecular events associated with increased tumor progression, tumor sections were examined for histopathological analysis. High cell density and reduced necrosis were clearly visible in the sections of both tumor types (B16F10 derived isograft as well as A375 derived xenograft) from metformin administered mice (Figure 2A and 2B). We noted that metformin enhanced proliferation and progression of A375 derived xenograft was phenotypically distinct as compared to the control tumor. This is suggestive of a grade advancement of primary tumor, evident by elongated morphology of nuclei compared to rounded morphology in the control tumors sections (unpublished information). Immunohistochemical staining of the cell cycle regulatory protein cyclin D1 (Figure 2C) was found to be higher in tumor section from metformin administered mice. Further, we validated the enhanced tumor growth by checking status of cell cycle regulatory proteins by immunoblotting of tumor lysates. We found that levels of molecules cyclin D1, CDK4, E2F1 and PCNA were increased significantly in the tumor lysates of metformin administered mice as compared to control, while p21 level was diminished (Figure 2D). These results indicate that metformin, irrespective of glycemic status of mice, promotes melanoma growth by modulating cell cycle regulatory proteins. Moreover, immunohistochemical analysis of tumor sections strengthened this observation, 
because metformin treatment enhanced protein levels of CD31, an endothelial marker (Figure 2E and 2F), and increased the serum level of VEGF (Figure 2G), suggesting that metformin promotes angiogenesis in melanoma tumors.

Next, we checked effect of metformin on the growth and proliferation of melanoma cells in vitro. In contrast to our in vivo findings, metformin treatment resulted in growth suppression of melanoma cells in vitro (Supplementary Figure S1A, S1B, S1C and S1D). Thereafter, we investigated the impact of complex I inhibition using metformin and phenformin on melanoma cells growth as both of these inhibited complex I activity
(Supplementary Figure S2). We found that metformin and phenformin caused growth arrest in melanoma cells grown under high glucose. However, in presence of low glucose, treatment with these agents resulted in cell death (Supplementary Figure S3A, S3B, S3C and $\mathrm{S} 3 \mathrm{D})$. It is likely that metformin mediated growth arrest is due to reduction in glucose level and extracellular acidification, of media (Supplementary Figure S4A and S4B). Interestingly, replacing the medium after every $12 \mathrm{~h}$ with fresh medium containing $25 \mathrm{mM}$ glucose increased clonogenic survival upon metformin treatment. As metformin-treated cells utilized glucose very rapidly in comparison to the control; therefore, replenishment
A

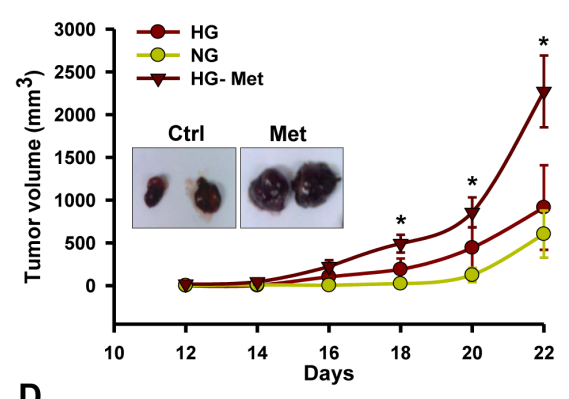

D

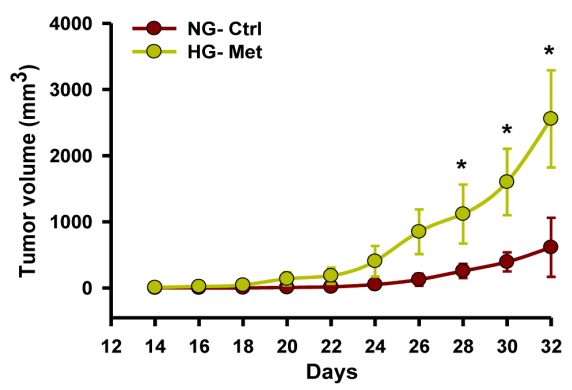

G

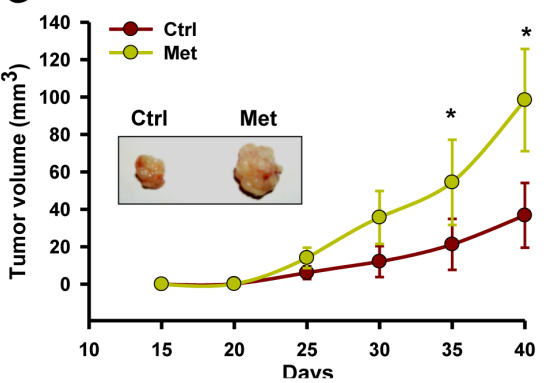

B

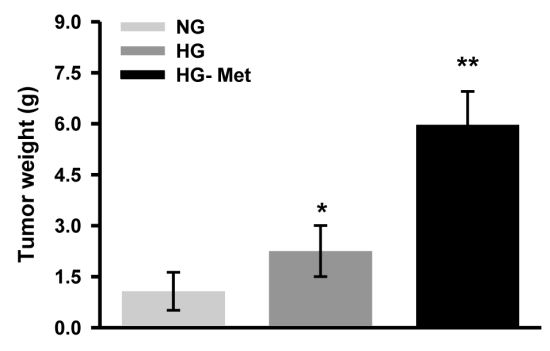

E

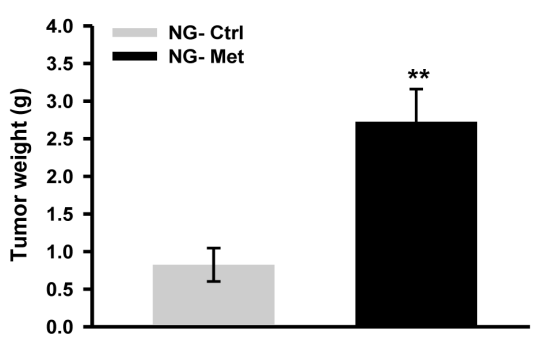

H

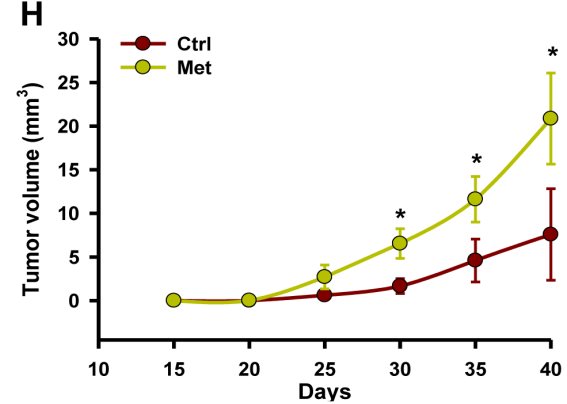

C

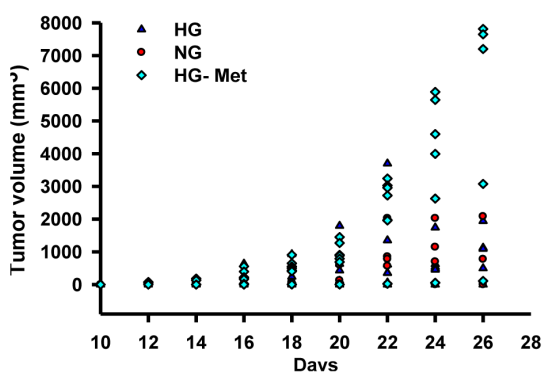

$\mathbf{F}$

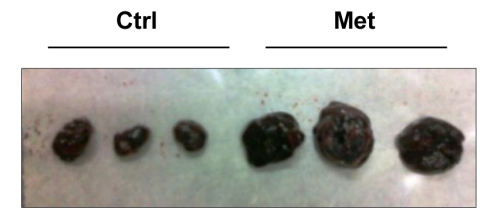

Figure 1: Metformin promotes melanoma tumor growth in mice. A.-C. C57BL/6J mice were made diabetic by injecting $50 \mathrm{mg} / \mathrm{kg}$ streptozotocin (STZ) intraperitoneally for 3 consecutive days. Tumor was developed by injecting $1 \times 10^{5} \mathrm{~B} 16 \mathrm{~F} 10 \mathrm{melanoma}$ cells subcutaneously in C57BL/6J mice, one week post STZ injection. Metformin $(200 \mathrm{mg} / \mathrm{kg})$ was administered in hyperglycemic mice orally before injecting the cells. Graph representing tumor progression A., tumor weight B., and tumor volume of individual mice C. in hyperglycemic mice. Results are given as means $\pm \mathrm{SD}(n=7)$. D. Tumor progression of B16F10 isograft in normoglycemic mice. Mice were administered with metformin $(200 \mathrm{mg} / \mathrm{kg})$ orally after the appearance of palpable tumor. E. and F. Weight and representative image of tumors excised from normoglycemic mice administered with or without metformin. Results are given as means \pm SD ( $n=5)$. G. Tumor progression of A375 xenograft in hyperglycemic mice administered with or without metformin $(200 \mathrm{mg} / \mathrm{kg})$. Results are given as means $\pm \mathrm{SD}(n=5)$. H. Tumor progression of A375 xenograft in normoglycemic mice administered with or without metformin $(200 \mathrm{mg} / \mathrm{kg})$. Results are given as means $\pm \mathrm{SD}(n=5)$. I. Weight of tumors excised from either hyperglycemic or normoglycemic mice administered with or without metformin. The values $* p<0.05,{ }^{*} p<0.01$ denote significant differences between the groups. (HG- hyperglycemic, NGnormoglycemic, Ctrl- control, Met- metformin). 
of medium is essentially required to maintain glucose level and $\mathrm{pH}$ thereby survival of cells in the presence of metformin (Supplementary Figure S4C and S4D). These results suggest that concentration of glucose available in the culture medium influences metformin's action.

\section{Inhibition of respiratory complex I activity promotes aerobic glycolysis}

Discrepancy in the outcome of metformin treatment in vivo and in vitro prompted us to explore the cause for the same. It is known that metformin exerts its action primarily by inhibiting mitochondrial OXPHOS enzyme complex I [27-29] and inhibition of complex I results in increased tumor growth and proliferation [14-18]. As we observed that metformin treatment caused acidification of culture medium due to enhanced aerobic glycolysis (Supplementary Figure 4A and 4B), we therefore speculated that this might be the reason for cell growth arrest. Thus, we measured level of glucose as well as lactate in the spent culture medium collected from control and metformin treated cells. Increased glucose utilization (as evident by the presence of less residual glucose in medium) and higher lactate level was detected in metformin treated cells as compared to the control (Figure $3 \mathrm{~A}$ and $3 \mathrm{~B})$.

To strengthen these findings, we further explored the expression pattern and activity of some of the proteins and enzymes involved in regulating glycolysis.
A
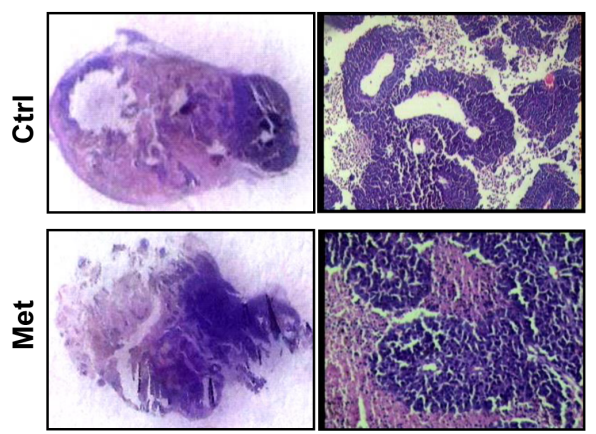

D

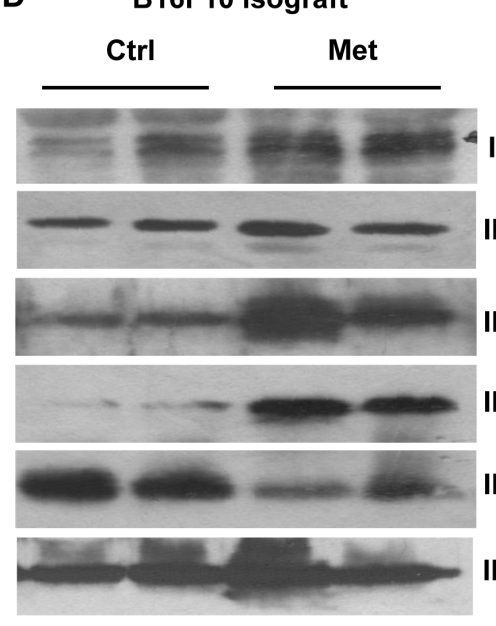

IB:E2F1

IB:CDK4

IB: p21
B
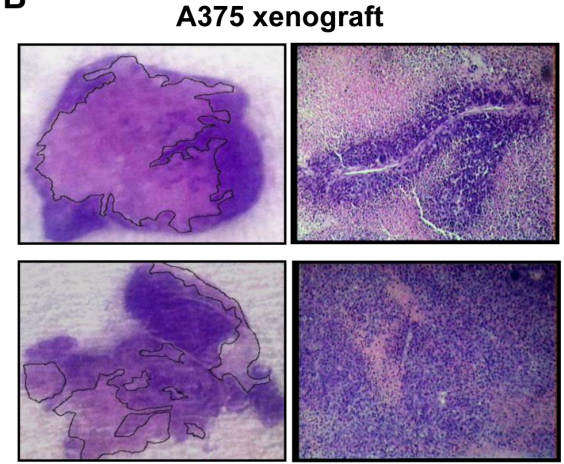

B16F10 isograft

IB: Cyclin D1

IB: PCNA

IB: $\beta$-Tubulin

E CD31
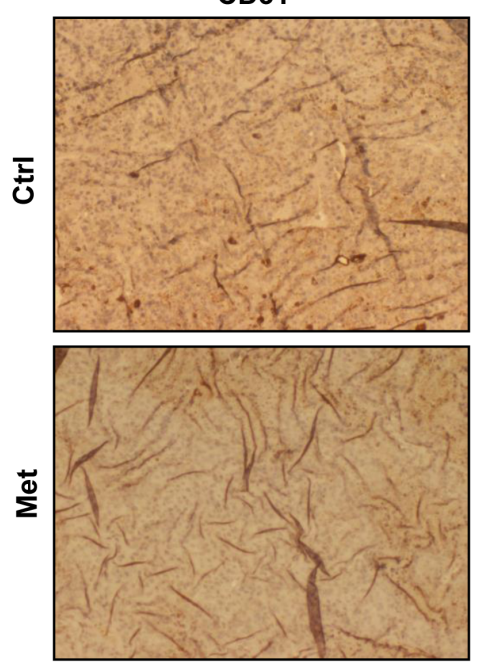

C
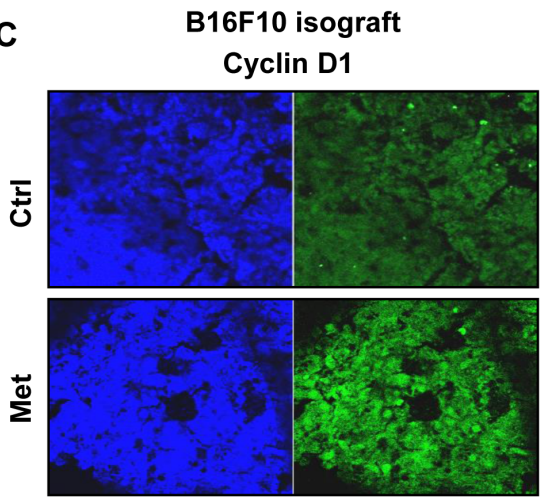

F
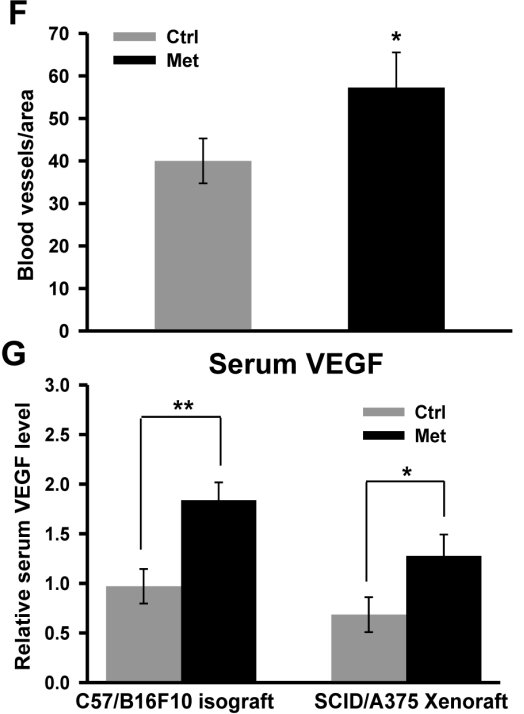

Figure 2: Metformin promotes melanoma tumor growth by inducing angiogenesis and by inhibiting necrosis. A. and B. Representative H\&E images of tumor sections of B16F10 isograft A. and A375 xenograft B. from control and metformin groups showing necrotic regions (pink) and healthy cells (blue). A. H\&E staining of B16F10 isograft section from control and metformin group. B. H\&E staining of A375 xenograft section from control and metformin groups. C. Representative immunoblots showing the expression of indicated cell cycle regulatory molecules in the lysate of B16F10 derived tumors from control and metformin groups. D. Representative immunohistochemical image showing the expression of cell cycle regulatory molecule cyclin D1 in the B16F10 isograft section from control and metformin groups. E. and F. Immunohistochemical analysis of angiogenesis marker CD31 in the tumor section of B16F10 isograft of control and metformin group G. Relative serum level of VEGF in control and metformin administered C57 and NOD/SCID mice. All these experiments were performed in normoglycemic mice. Data were represented as means $\pm \mathrm{SD}$. The values $* p<0.05, * * p<$ 0.01 denote significant differences between the groups. (HG- hyperglycemic, NG- normoglycemic, Ctrl- control, Met- metformin). 
We found that metformin increased protein levels of key glycolytic molecules GLUT1, LDHA and ChREBP in a concentration dependent manner (Figure 3C). These results suggest that inhibition of complex I activity by metformin could possibly enforce cancer cells to adopt glycolytic route for ATP generation causing enhancement in tumor progression in mice.

To evaluate whether glycolytic phenotype can also be induced in vivo upon inhibition of complex I, we first checked the level of glucose in serum collected from mouse bearing tumor along with normoglycemic mice treated or untreated with metformin. Significant decline in the level of serum glucose was observed in metformin administered normoglycemic, tumor bearing mice $(104.3 \pm 13.7 \mathrm{mg} / \mathrm{dl}$ in $\mathrm{C} 57 \mathrm{BL} / 6 \mathrm{~J}$, and $134.0 \pm 7.2$ $\mathrm{mg} / \mathrm{dl}$ in NOD/SCID) as compared to untreated control $(139.7 \pm 16.3 \mathrm{mg} / \mathrm{dl}$ in C57BL/6J, and $168.0 \pm 8.5 \mathrm{mg} / \mathrm{dl}$ in NOD/SCID) (Figure 3D and 3E). Similarly, metformin treatment caused reduction in serum glucose in tumor bearing hyperglycemic mice (Met, $237.3 \pm 30.0 \mathrm{mg} / \mathrm{dl}$ in C57BL/6J, and $227.3 \pm 12.3 \mathrm{mg} / \mathrm{dl}$ in NOD/SCID) as compared to control $(388 \pm 31.5 \mathrm{mg} / \mathrm{dl}$ in $\mathrm{C} 57 \mathrm{BL} / 6 \mathrm{~J}$, and $409.3 \pm 18.6 \mathrm{mg} / \mathrm{dl}$ in NOD/SCID mice) (Figure 3D and $3 \mathrm{E})$. Secretion of lactate is a hallmark of glycolytic tumors. Therefore, we checked lactate level which was found to be very high in the serum of tumor bearing normoglycemic as well as hyperglycemic mice administered with metformin (Figure $3 \mathrm{~F}$ and $3 \mathrm{G}$ ). Elevated serum LDH is associated with high grade aggressive tumors and poor prognosis in case of metastatic melanoma [8-10]. Thus, serum
A
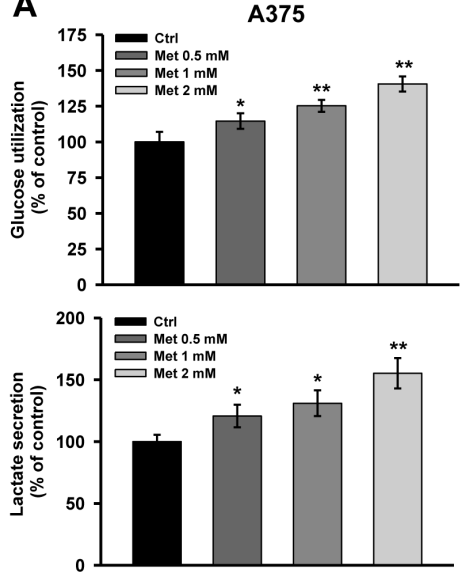

B
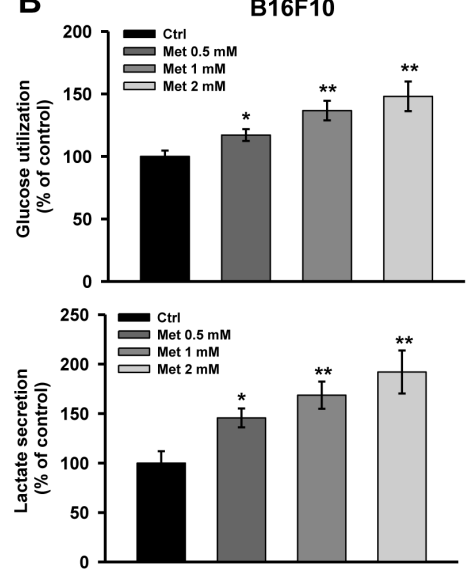

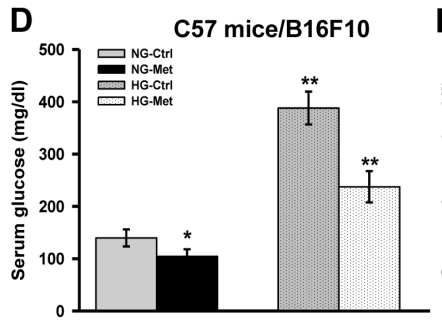

H

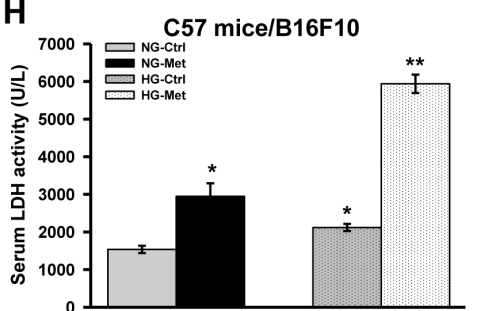

SCID mice/A375

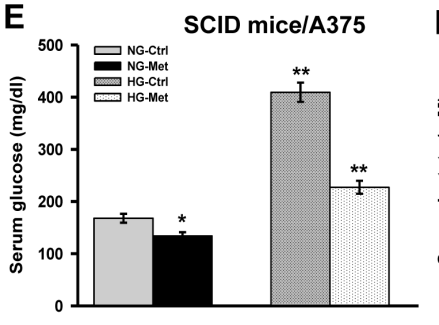

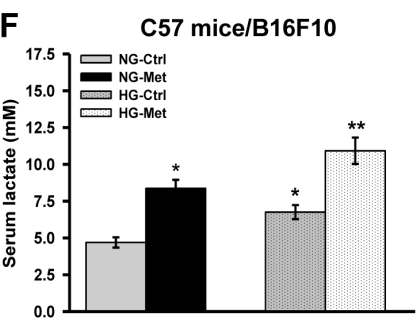

G SCID mice/A375
C
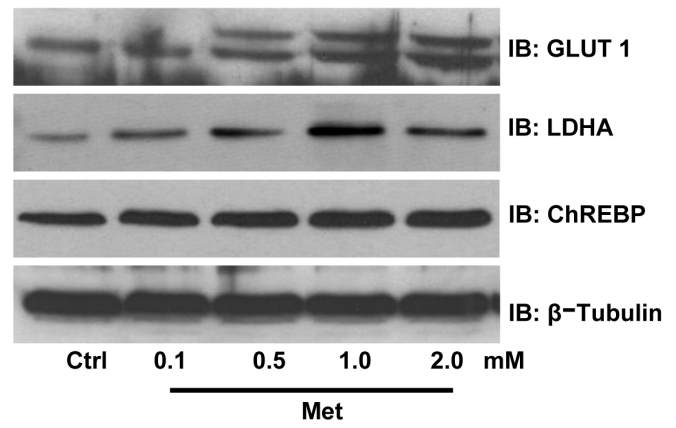

I

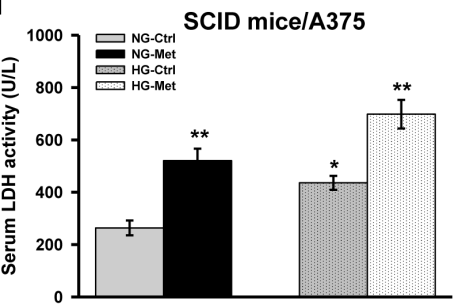

$\mathbf{J}$

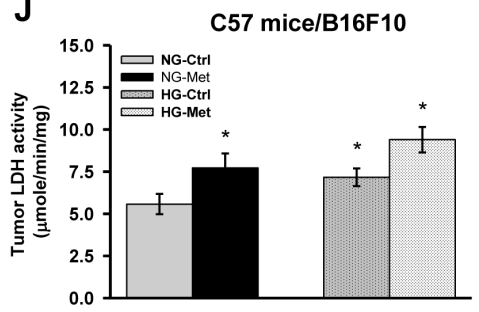

Figure 3: Complex I inhibition induces aerobic glycolysis. A. and B. A375 and B16F10 cells were cultured in presence of different concentrations of metformin $(0.5,1.0$, and $2.0 \mathrm{mM})$ for $36 \mathrm{~h}$. Glucose and lactate level in the spent culture medium was determined by using enzymatic assay kits. C. Representative immunoblots showing protein level of indicated molecules in whole cell lysate of B16F10 cells treated with metformin for $36 \mathrm{~h}$. D. and E. Relative level of glucose in serum collected from normoglycemic or hyperglycemic C57BL/6J mice bearing B16F10 isograft D. and NOD/SCID mice bearing A375 xenograft E. from metformin administered groups $(n=4)$. F. and $\mathbf{G}$. Relative levels of lactate in serum collected from normoglycemic or hyperglycemic C57BL/6J mice bearing B16F10 isograft F., and NOD/ SCID mice bearing A375 xenograft G. from metformin administered groups $(n=4)$. H. and I. Serum LDH activity in normoglycemic or hyperglycemic C57BL/6J mice bearing B16F10 isograft $\mathbf{H}$. and NOD/SCID mice bearing A375 xenograft I. from control and metformin administered groups $(n=4)$. J. LDH activity in the B16F10 isograft from metformin administered normoglycemic and hyperglycemic mice. Values are represented as mean $\pm \mathrm{SD}$. The values $* p<0.05, * * p<0.01$ denote significant differences between the groups $(n>3$ at the least). (NG-normoglycemic, HG-hyperglycemic, Ctrl- control, Met-metformin). 
LDH activity was monitored and was found to be very high in the serum collected from hyperglycemic and normoglycemic mice administered with metformin as compared to control (Figure 3H and 3I). Furthermore, increased LDH activity was detected in tumor tissues of metformin administered mice compared to the untreated control (Figure 3J).

\section{Inhibition of complex I together with LDH or lactate generation is synthetically lethal to melanoma cells}

To explore the possibility whether metformin promoted glycolysis or excess lactate generation is the major cause of increased growth and proliferation of melanoma tumors, lactate generation was inhibited by using LDH inhibitor oxamate and PDK1 inhibitor DCA. We found that oxamate and DCA alone have inhibitory effect on melanoma cell growth (Figure 4A, 4B and 4C; Supplementary Figure S5). Reduced cell survival was observed upon treatment with oxamate or DCA together with metformin (Figure 4A, 4B and 4C). Similarly, other well-known glycolytic inhibitors like phloretin (GLUT1 inhibitor), 2-deoxy-D-glucose (2DG), and iodoacetate also restricted proliferation of melanoma cells treated with metformin (Supplementary Figure S6A and S6B). Enhanced glucose uptake through GLUT1 and increased aerobic glycolysis through LDHA and PDK1 is the hallmark of cancer cells. Therefore, we chose oxamate and DCA over other glycolytic inhibitors.

Next, to check the long term survivability of
A

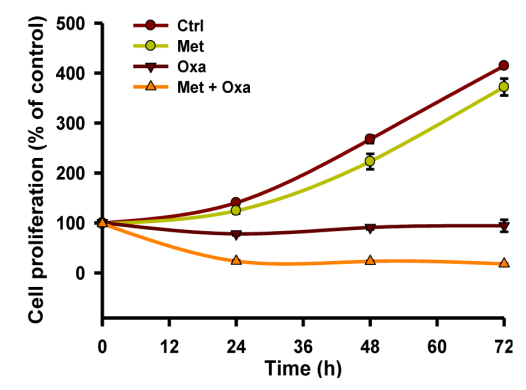

B

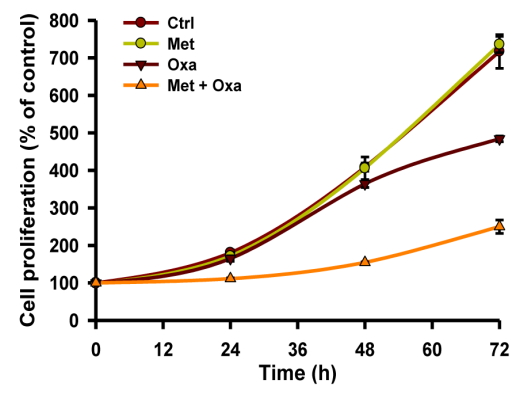

C

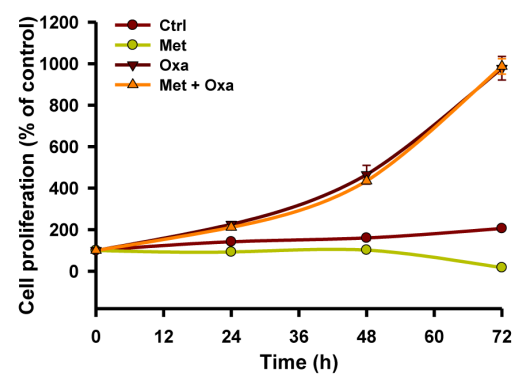

A375

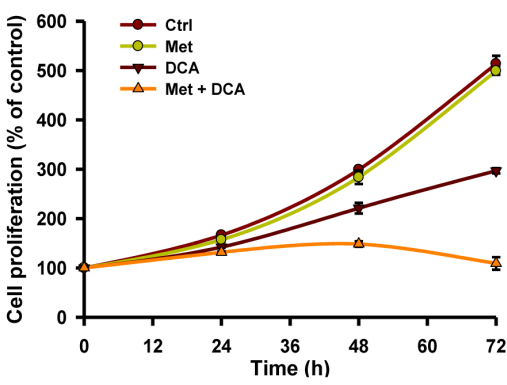

B16F10

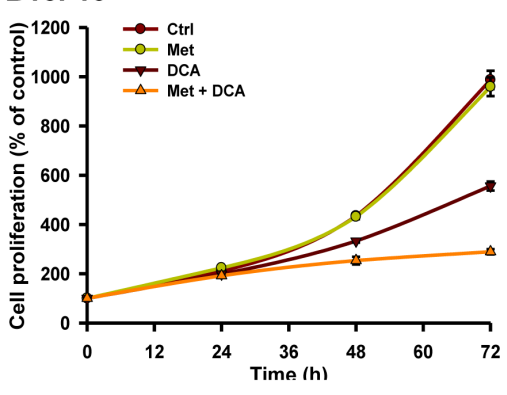

SKMel28

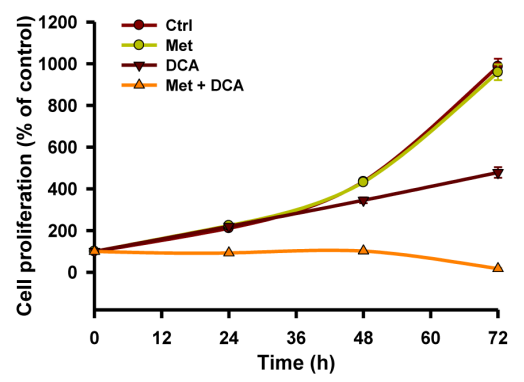

D $\quad$ A375

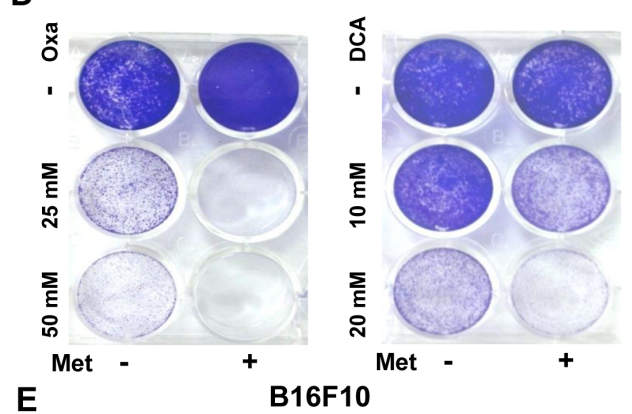

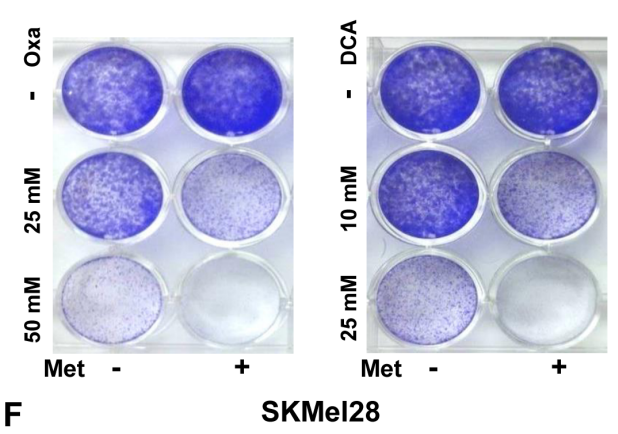
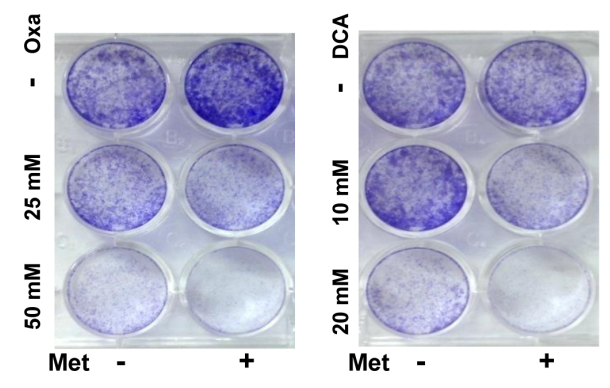

Figure 4: Inhibition of complex I sensitizes cancer cells to LDH and PDK1 inhibitors oxamate and DCA. A.-C. Effect of oxamate and DCA on growth of A375, B16F10 and SKMel28 cells treated with or without metformin. Cells were treated with 25 mM oxamate or $10 \mathrm{mM}$ DCA either alone or with $2 \mathrm{mM}$ metformin for indicated time point. Cell viability was assessed by MTT assay. D.-F. Survival of A375 D., B16F10 E. and SKMel28 F. cells grown in the presence of oxamate ( 25 or $50 \mathrm{mM})$ or DCA (10 or $20 \mathrm{mM})$ alone or together with $2 \mathrm{mM}$ metformin for $48 \mathrm{~h}$. Representative images showing the long term survival of cancer cells treated with indicated concentrations of DCA and oxamate alone or together with metformin $(2 \mathrm{mM})$ and allowed to grow for $48 \mathrm{~h}$. Medium was replaced with fresh medium without any inhibitors. Medium was changed every 2-3 days and allowed to grow in drug free medium for further 10-15 days. Colonies were stained with crystal violet and photographed. All values are represented as mean \pm SD. (Ctrl- control, Met- metformin, Oxa- oxamate). 
melanoma cells in the presence of metformin and oxamate/ DCA alone or in combination together, we performed clonogenic survival assay. No surviving colonies were detected in melanoma cells treated with oxamate and metformin together (Figure 4D, 4E and 4F). Similar results were also obtained in cells treated with metformin and DCA together (Figure 4D, 4E and 4F). Subsequently, we checked whether inhibition of these two enzymes induced death in melanoma cells as evident by Annexin $\mathrm{V}$ and PI staining. All these agents alone caused growth arrest, but did not induce apoptosis. However, increased apoptosis was detected in A375 and B16F10 cells treated with oxamate/DCA together with metformin as compared to single agent alone (Figure 5A and 5B). This observation was further confirmed by immunoblotting for the apoptotic markers PARP1, Bax and Bcl-2 (Figure 5C and 5D). Increased PARP cleavage and Bax level while decreased level of antiapoptotic protein Bcl-2 was detected in cells treated with metformin and oxamate/DCA together as compared to single agent alone (Figure 5C and 5D). These results indicate that inhibition of complex I and LDH together can promote induction of apoptosis.

Next, we have checked the impact of metformin and oxamate/DCA either alone or in combination on the survival of non-cancerous cells. We used three different non-cancerous cell lines namely AML12 (mouse hepatocytes), L6 (rat muscle cells) and MEF (mouse embryonic fibroblasts) to test the effect of combination treatment. Although, combination of metformin and oxamate/DCA slackened the proliferation of these cells (Supplementary Figure S7A, S7B and S7C), it did not affect the cell viability (Supplementary Figure S7D), indicating that this combination is effective in selectively killing cancer cells.
A

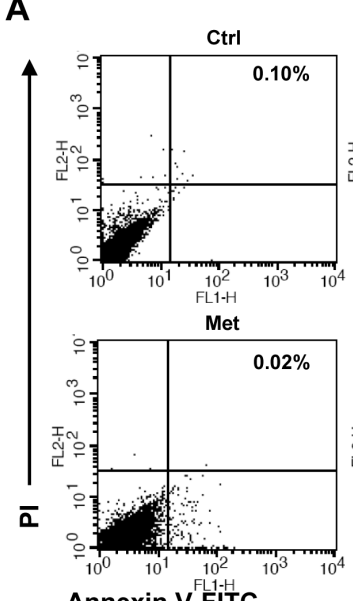

Annexin V-FITC

B

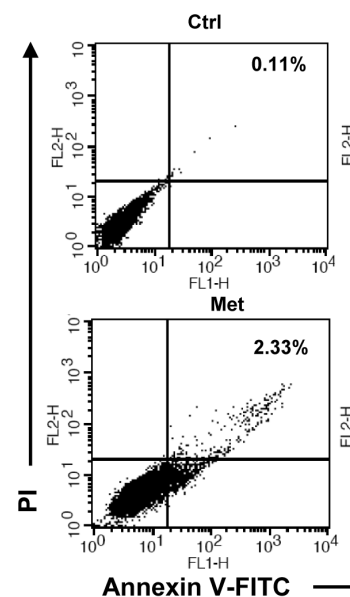

A375
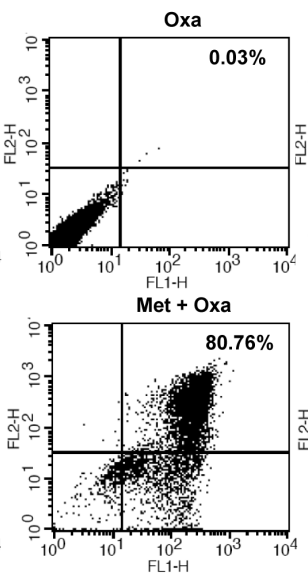

B16F10

Oxa
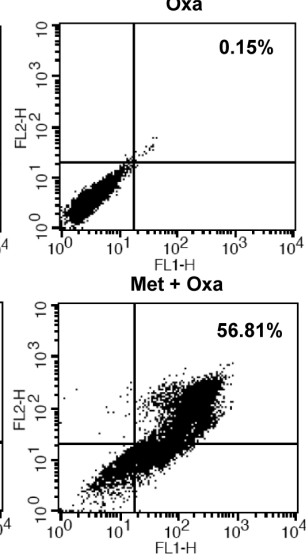
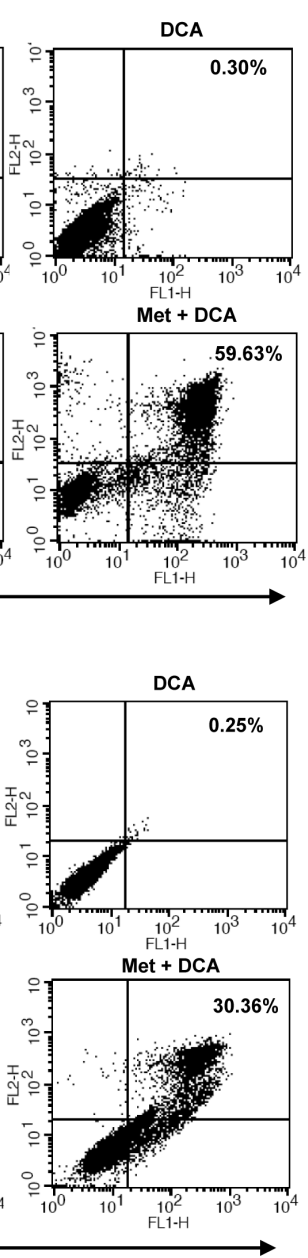

C

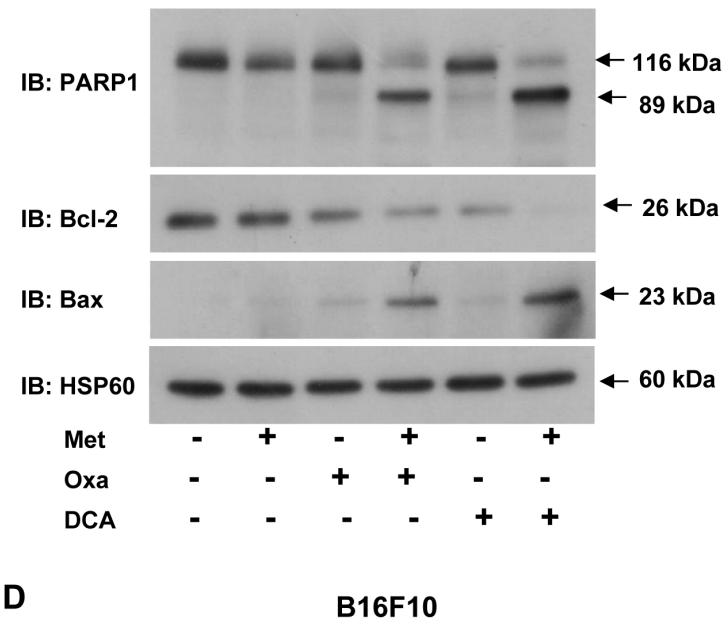

IB: PARP1

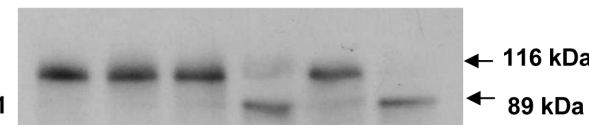

IB: Bcl-2

IB: Bax

IB: HSP60

Met

Oxa DCA

A375

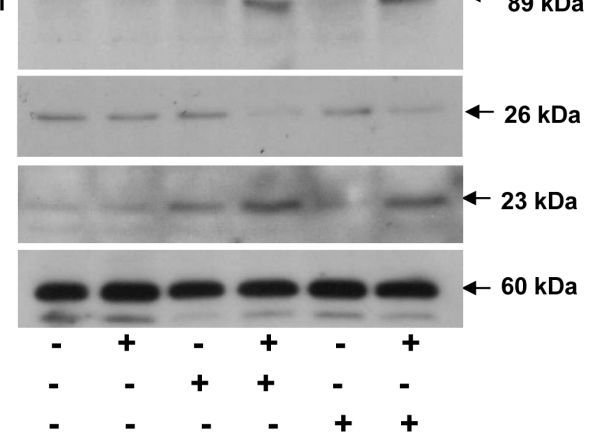

Figure 5: Simultaneous blocking of lactate generation and complex I induces apoptosis in melanoma cells. A. and B. A375 and B16F10 cells were grown in DMEM with or without $50 \mathrm{mM}$ oxamate and $20 \mathrm{mM}$ DCA either alone or together with $2 \mathrm{mM}$ metformin for $36 \mathrm{~h}$. Apoptosis was detected by using Annexin V and PI dual positive cells via flow cytometry. C. and D. Representative immunoblots showing the protein levels of apoptotic markers PARP1, Bax and antiapoptotic molecule Bcl-2 in A375 C. and B16F10 cells D. grown under above mentioned conditions. HSP60 was used as a loading control. (Ctrl- control, Met- metformin, Oxa- oxamate). 


\section{Blocking complex I and lactate generation imposes metabolic catastrophe}

To ensure whether oxamate and metformin cotreatment affects metabolism of melanoma cells, we measured metabolic parameters in presence of these inhibitors. Metformin treatment elevated glycolysis, while oxamate treatment resulted in decrease in glucose utilization and lactate secretion (Figure 6A and 6B). Interestingly, glucose utilization and lactate secretion was inhibited significantly upon treating cells with both oxamate and metformin together (Figure 6A and 6B). Additionally, both oxamate as well as metformin reduced
ATP levels by inhibiting substrate level phosphorylation and OXPHOS respectively (Figure 6C). Also, a significant decline in ATP level was detected in cells treated with oxamate and metformin together (Figure 6C). Further, to confirm the involvement of $\mathrm{LDH}$ in melanoma cell growth and proliferation, knock down of LDHA (LDHAKD) was performed using specific siRNA (Figure 6D). Increased cell death was observed in LDHA-KD cells treated with metformin or phenformin (Figure 6E). A significant reduction in glycolysis (as evident by decreased glucose utilization and lactate secretion) and ATP level was observed in LDHA-KD cells as compared to control (Figure 6F, 6G and 6H). Moreover, decrease in glycolytic rate as well as a sharp decline in ATP level was observed
A

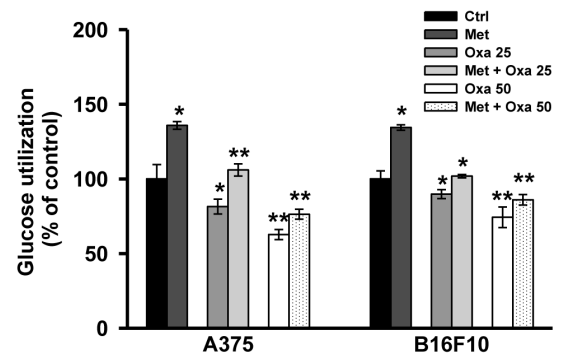

D
B

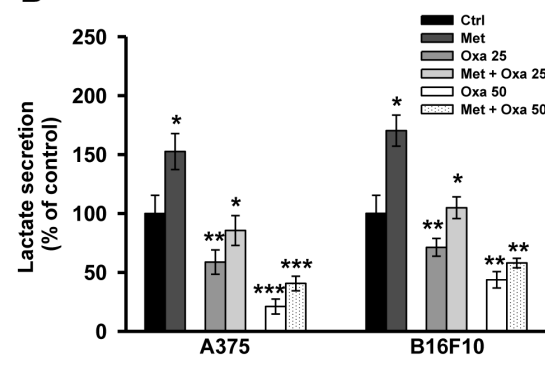

C

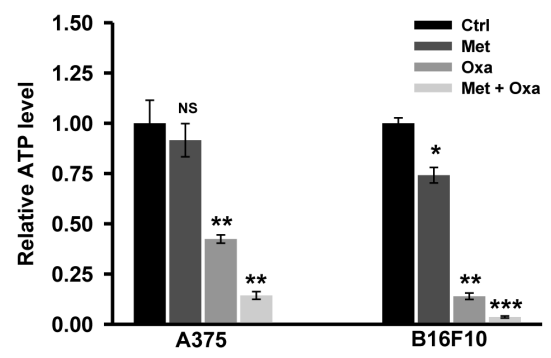

E

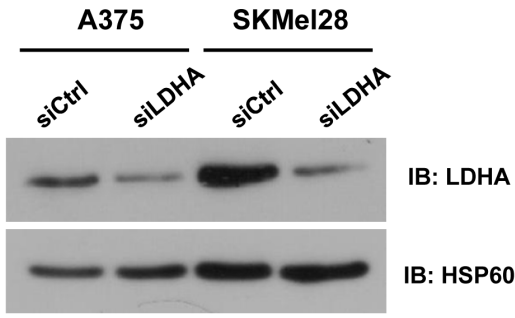

$\mathbf{F}$

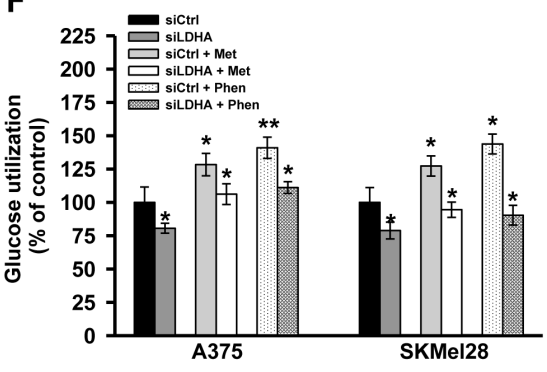

G

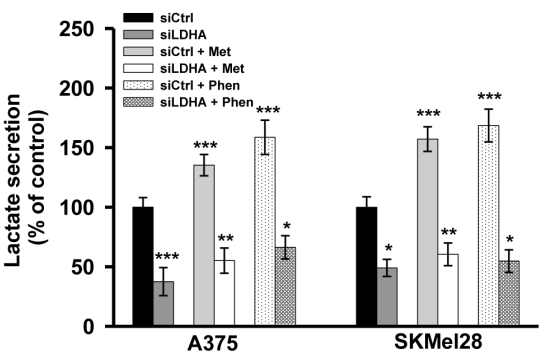

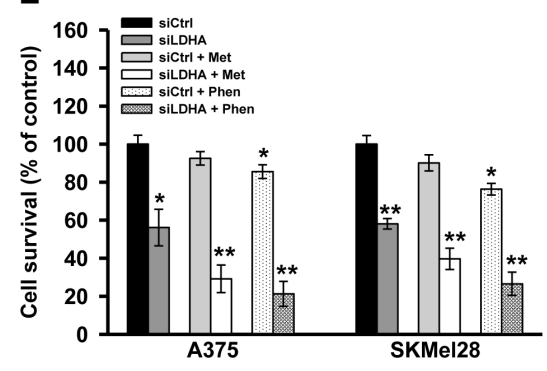

H

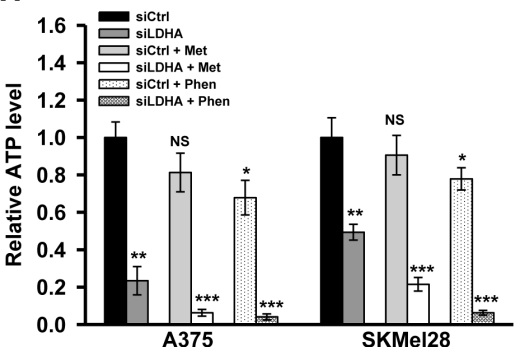

Figure 6: Inhibition of complex I and lactate generation together induces metabolic catastrophe. $\mathbf{A}$. and B. A375 and B16F 10 cells were treated with oxamate $(25$ and $50 \mathrm{mM}$ ) either alone or with $2 \mathrm{mM}$ metformin for $36 \mathrm{~h}$. Level of glucose and lactate in the culture medium was measured as mentioned in method section. C. Relative ATP levels in A375 and B16F10 cells grown in the conditions mentioned in A.. D. Human melanoma cells (A375 and SKMel28) were grown in 96 well plates (60\% confluency) and transfected with control and LDHA specific siRNA as described in methods section. These cells were treated with either metformin $(2 \mathrm{mM})$ or phenformin $(100 \mu \mathrm{M})$ for additional $48 \mathrm{~h}$. Inhibition of LDHA expression was confirmed by immunoblotting. E. Survival of A375 and SKMel28 upon knocking down LDHA grown in presence or absence of metformin and phenformin. F.-H. A375 and SKMel28 cells were grown in $35 \mathrm{~mm}$ culture dish for $24 \mathrm{~h}$. These cells were transfected with either control or LDHA specific siRNA and allowed to grow for further $24 \mathrm{~h}$. Cells were treated with either $2 \mathrm{mM}$ metformin or $100 \mu \mathrm{M}$ phenformin for additional $48 \mathrm{~h}$. Glucose utilization F., lactate secretion G. and total cellular level of ATP H. was determined in melanoma cells as described in method section. Values are represented as mean \pm SD. The values $* p<0.05,{ }^{* *} p<0.01, * * * p<0.001$ denote significant differences between the groups $(n>3$ at the least). (Ctrl- control, Met- metformin, Oxa- oxamate, Phen- phenformin). 
in LDHA-KD cells treated with either metformin or phenformin (Figure 6F, 6G and 6H). These results indicate that simultaneous inhibition of both complex I and LDH or lactate generation pathway induces metabolic catastrophe owing to the disruption of cellular ATP pool, eventually leading to growth arrest and cell death.

\section{Simultaneous inhibition of complex I and LDH by metformin and oxamate retards tumor progression in mice}

To verify whether combination of oxamate and metformin is also effective in diminishing tumor progression, tumors were developed by injecting B16F10 cells in $\mathrm{C} 57 \mathrm{BL} / 6 \mathrm{~J}$ mice. After tumors reached up to 50 $\mathrm{mm}^{3}$ in size, mice were randomized into four groups; (a) control, (b) metformin, (c) oxamate, and (d) metformin and oxamate together treated mice. We noticed that mice administered with metformin developed larger tumor as compared to the untreated control (Figure 7A, 7B and 7C). While in mice administered with oxamate, tumors progressed at a slower rate than the untreated control as well as in mice administered with metformin (Figure 7A). Interestingly, we observed that oxamate retarded tumor progression dramatically when administered together with metformin as evident by reduction in tumor volume and tumor weight (Figure 7A, 7B and 7C).

Further, to confirm whether abrogation of metformin induced tumor progression by oxamate is a consequence of reduction in aerobic glycolysis, we measured metabolic parameters in vivo. Metformin administered mice had low serum glucose, higher lactate and LDH levels in serum as compared to control, whereas relatively higher serum
A

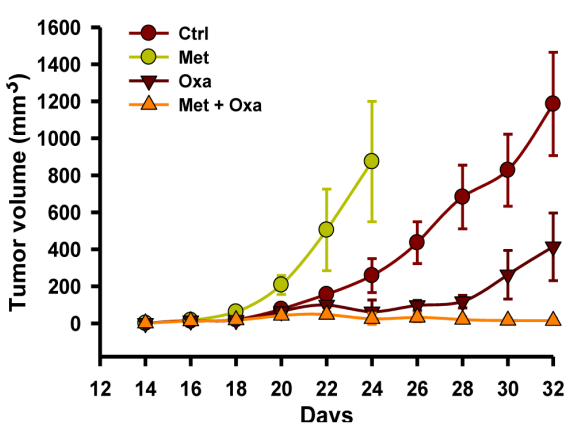

D

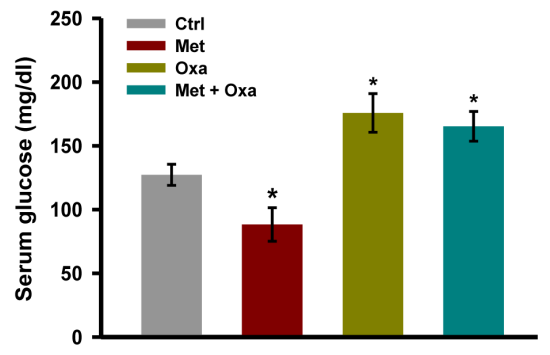

G

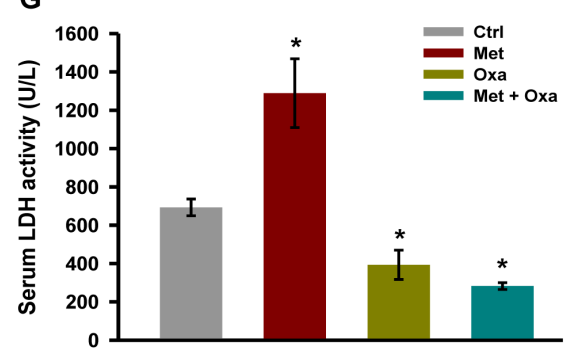

B

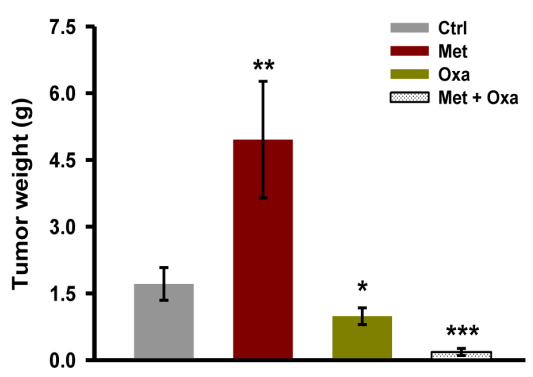

E
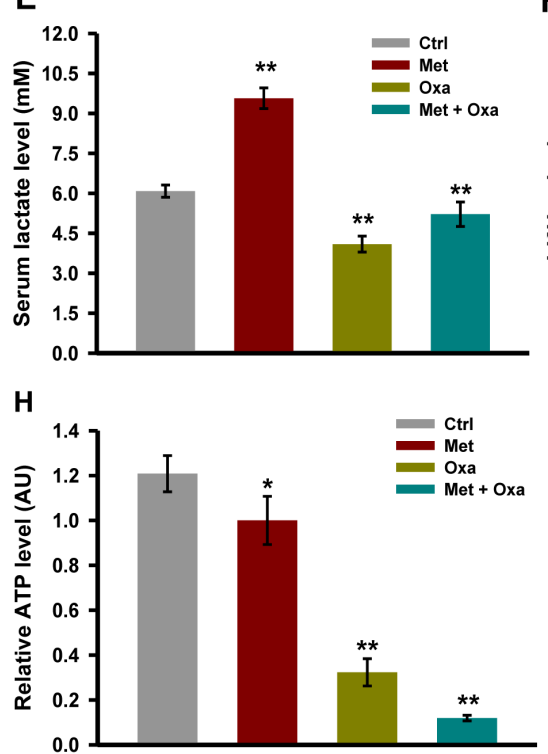

C

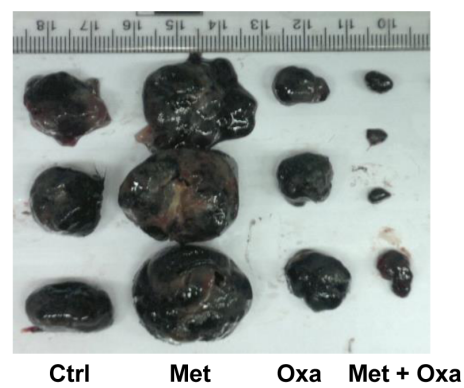

$\mathbf{F}$

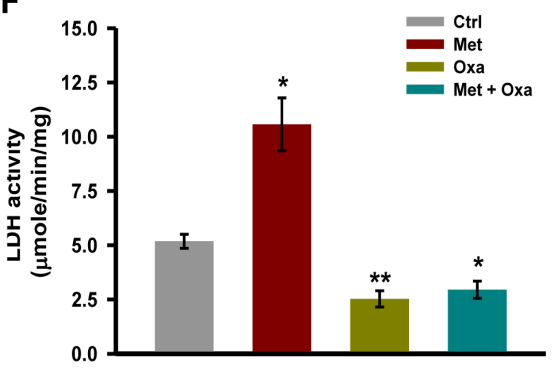

I

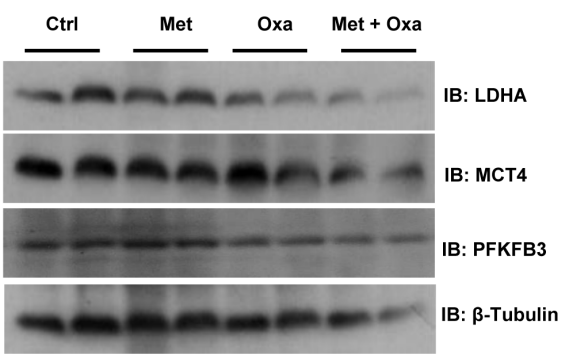

Figure 7: Inhibition of LDH activity restricts tumor progression of melanoma tumor upon complex I inhibition. A. Progression of B16F 10 isograft in C57BL/6J mice administered with metformin $(200 \mathrm{mg} / \mathrm{kg}$, orally) and oxamate $(500 \mathrm{mg} / \mathrm{kg}$, orally) either alone or together $(n=5)$. Values are represented as mean \pm SD. B. and $\mathbf{C}$. Tumor weight and representative image of tumors excised from mice of indicated groups. D. and E. level of glucose and lactate in the serum collected from tumor bearing mice with indicated treatment groups $(n=4)$ F. Enzymatic activity of LDH in tumor lysate $\mathbf{G}$. LDH activity in serum from the mice of indicated treatment groups $(n=3)$. H. Relative ATP levels in the tumors of indicated treatment groups $(n=3)$. I. Immunoblots showing protein levels of indicated molecules in the whole tumor lysates. Values are represented as mean \pm SD. The values ${ }^{*} p<0.05,{ }^{* *} p<0.01$ denote significant differences between the groups. (Ctrl- control, Met- metformin, Oxa- oxamate). 
glucose and low lactate level were detected in the mice treated with oxamate alone or metformin together with oxamate (Figure 7D and 7E). Activity of LDH enzyme was significantly diminished in the tumors excised from mice treated with oxamate alone or metformin together with oxamate (Figure 7F). Relatively very low level of ATP was detected in the tumors of mice administered with both oxamate and metformin together as compared to single agent alone. However, we did not observe significant changes in the protein levels of molecules regulating glycolysis (Figure 7I). Importantly, no significant change in body weight was detected in the mice receiving combination treatment and no possible adverse side effects or gross symptoms of generalized toxicity were observed upon visual inspection (Supplementary Figure S8A). Moreover, seemingly no pathological abnormalities were observed in the vital organs like lung, liver, kidney and heart of these mice (Supplementary Figure S8B). These results suggest that this combination does not exert generalized toxicity and effective in retarding tumor progression in mice.

\section{DISCUSSION}

Cancer cells including melanoma cells divert huge amount of carbon flux to glycolysis [5-7]. This helps the cells to generate ATP and other building blocks for rapid tumor growth [5]. Several reports suggest that targeting metabolic pathways reduces tumor progression and cell growth in vitro [40-42]. In the present study, we demonstrate that metformin promotes melanoma growth by elevating glycolysis owing to the inhibition of complex I function, while inhibition of LDH causes growth arrest in cells. Inhibiting lactate generation in melanoma cells treated with metformin affects cell survival thereby causing reduction in tumor progression (Figure 8).

Consequences of inhibiting complex I on growth of cancer cells are not clearly understood though, reports suggest that complex I inhibition leads to cellular transformation and enhances cell growth [14-18]. Conversely, inhibition of complex I has also been reported to retard tumor progression in mice [30]. These diverse outcomes are likely to be dependent on the availability of nutrients in the tumor microenvironment. It has been reported that when glucose is available in abundance, inhibition of complex I promote glycolysis and rapid proliferation of cells, while it induces cell death under metabolic stress conditions [43]. In this study, we observed that inhibition of complex I by metformin promotes melanoma tumor progression in mice.

While metformin has been shown to inhibit proliferation of many cancer cells and also restricts tumor progression of xenograft in mice [33,34], it is known to exert growth inhibitory as well as growth promoting effects in melanoma [35-37]. Interestingly, we detected that $\mathrm{B} 16 \mathrm{~F} 10$ and $\mathrm{A} 375$ derived tumors grew rapidly in mice administered with metformin and growth rate varied depending on glycemic status of mice (Figure 2D and 2E). This observation concurs with recent report demonstrating that metformin facilitates tumor progression of BRAF mutant melanoma cells [35].

Disparity in the action of metformin on the growth of melanoma cells in vitro and in vivo is likely to be influenced by the availability of glucose and lactate concentration which might influence its action. Metformin inhibits cell growth and induces apoptosis under glucose limiting conditions [43], while we noticed that in presence of high glucose it causes growth arrest without affecting cell death. We reasoned for this discrepancy that cancer cells derive ATP via OXPHOS under metabolic stress, whereas when glucose is abundant ATP is derived mainly through glycolysis. Inhibiting complex I under high glucose condition further promotes glycolysis resulting in excess lactate generation, and occurrence of this phenomena has been reported earlier [44]. Collectively, these findings suggest that growth arrest induced by metformin in melanoma cells in vitro is a consequence of acidification of medium due to excess lactic acid accumulation because of rapid utilization of available glucose. Notably, metformin induced growth arrest can be prevented by replenishing medium frequently to maintain optimum growth conditions, as metformin treated cells required more glucose to proliferate due to enhanced aerobic glycolysis. This mimics in vivo condition wherein probably rapid, constant circulation of access lactic acid allows cancer cells to use more glucose which helps in rapid proliferation. Moreover, lactate can also be utilized by cancer cells in tumor [45, 46]. Additionally, it has been reported that metformin induces angiogenesis via elevating VEGF level $[35,47]$. We report that inhibition of complex I increases lactate production and it has been previously suggested that the glycolytic switch enhances angiogenesis [48, 49]. Our results show a positive correlation between serum lactate and VEGF level in mice administered with metformin. Therefore, it is likely that metformin-enhanced tumor growth is facilitated by lactate induced angiogenesis that can be mediated by VEGF [48]. Furthermore, we observed increased level of E2F1, an important cell cycle regulatory molecule, in the tumors excised from mice administered with metformin. In addition to promoting cell proliferation, E2F1 also regulates many genes involved in glycolysis [50] which is essential for rapid growth of cancer cells. Therefore, it is likely that, E2F1 might play an important role in mediating metformin-induced rapid tumor progression probably via regulating aerobic glycolysis.

Glycolytic inhibitors such as 2-deoxy glucose, lonimide, 3-bromopyruvate, DCA, and drugs interfering with metabolic pathways have shown promising outcome in suppressing tumor growth [40-42, 51-53]. In addition, targeting lactate generation pathway is appealing especially in glycolytic cancers $[54,55]$. Melanoma cells 
are metabolically glycolytic, thereby rely primarily on the high activity of LDH for ATP generation [6]. Melanoma cells overexpress $\mathrm{LDH}$ and high serum level often correlates with poor prognosis and patient survival [3, 8 -10]. Our results indicate that disrupting the conversion of pyruvate to lactate profoundly affects proliferation of melanoma cells. This is in agreement with the reports that tumors of glycolytic cell types are more susceptible towards inhibition of LDH-A with FX11 [56].

$\mathrm{LDH}$ plays an important role in metabolic homeostasis and tumor maintenance [12, 57]. We used oxamate and DCA to inhibit lactate generation in melanoma cells. DCA is an orally deliverable small molecule that has been used for treatment of lactic acidosis, and restoration of OXPHOS functionality by DCA has been shown to induce cell death $[52,53]$. Moreover, DCA has previously been shown to reduce lactate production and triggers apoptosis in melanoma

cells [58, 59]. Oxamate, an analog of pyruvate, is also used to inhibit LDH. A recent study by Miskimins et al., suggests that targeting complex I and LDH together can be a promising strategy to halt growth of aggressive cancers [60]. Concurrence with this, we also noticed that preventing lactate generation and simultaneously inhibiting complex I by oxamate/DCA or by LDH specific siRNA and metformin respectively results in depletion of cellular ATP pool. Decline in cellular ATP pool evokes metabolic catastrophe which leads to apoptosis in melanoma cells. Metabolic catastrophe-induced cell death is considered as a promising strategy to halt cancer progression [61]. Moreover, our study signifies the distinct role of complex I and LDH in cell proliferation, and these two constitutes ATP generating route either through OXPHOS or substrate level phosphorylation respectively. Blocking either of the enzymes alone does not induce cell death as cells can switch to alternative pathway for

\section{C}

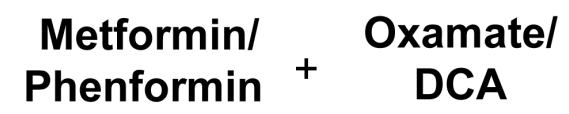

\section{Metformin/ Phenformin}

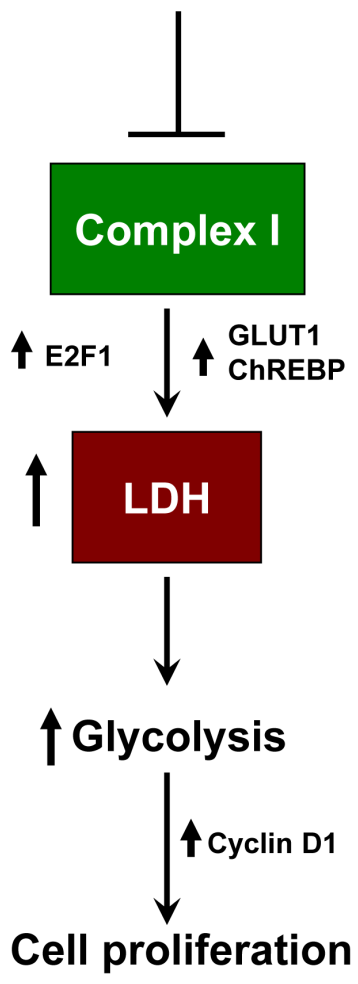

B

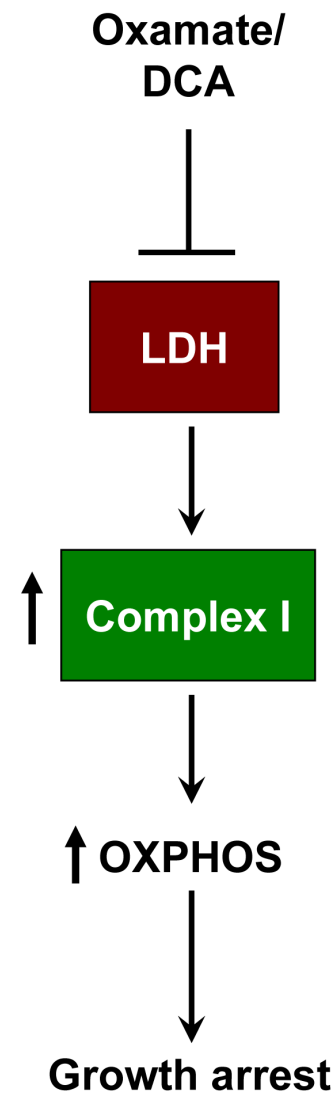
Phenformin ${ }^{+}$DCA

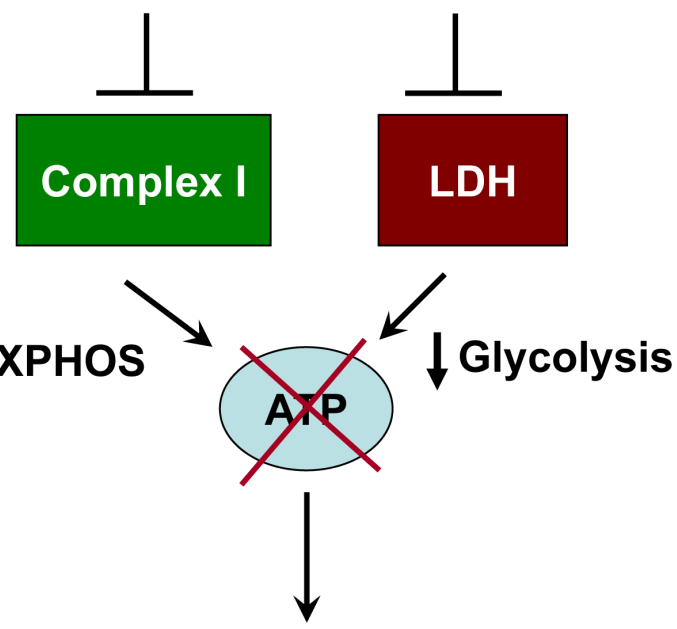

Metabolic catastrophe

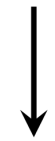

\section{Apoptosis}

\section{Synthetic lethality}

Figure 8: Schematic representation of synthetic lethality induced by combination of metformin and oxamate treatment in melanoma. A. Inhibition of respiratory complex I by metformin or phenformin alone results in elevation of glycolysis owing to the activation of lactate dehydrogenase (LDH). Generation of building blocks and ATP exclusively through glycolysis helps in rapid tumor growth. B. Targeting LDH or lactate generation by oxamate and DCA or by siRNA causes activation of OXPHOS and subsequent ATP generation. However this leads to suppression of cell proliferation without inducing cell death. C. Blocking both the enzyme together induces metabolic catastrophe owing to the depletion of cellular ATP pool. This leads to the initiation of apoptosis, and suppression of tumor growth. Complex I and LDHA form a synthetically lethal pair in melanoma cells. 
ATP generation. Whereas, simultaneously inhibiting both of these two, induces apoptosis. This clearly indicates that cells depend on the function of these two enzymes which form synthetically lethal pair, which is a promising phenomenon that can be employed for selective targeting of melanoma cells $[62,63]$. Given that E2F1 is involved in regulating apoptosis [64], it is likely that the apoptosis induced by the combination of metformin and oxamate/ DCA might involve E2F1. Metformin promotes apoptosis in cancer cells via activating p53 [37]. However, in case of melanoma, role of p53 is not clear. As the literature suggests, p53 is non-functional in melanoma and its levels are paradoxically elevated in advanced grades of melanoma [65-67]. Previously, we have reported that elevated level of p53 is associated with increase in tumor growth [68]. Therefore, it is unlikely that $\mathrm{p} 53$ is involved in apoptosis induced by the combination treatment and, thus, more studies are needed to evaluate the functionality of E2F1 and p53 in melanoma.

While using combinations of different drugs which can synergistically promote cancer cell death, this may also enhance toxicity to normal cell. Therefore, it is crucial to access the impact of the combination treatment on normal cells. Importantly, our data suggest that this combination is effective in killing cancer cells both in vitro as well in vivo, and has least impact on the survival of normal cells. The differential sensitivity between melanoma and normal cells due to metformin and oxamate/DCA combination can be attributed to the fact that melanoma cells are highly glycolytic and overexpress molecules involved in lactate generation and secretion as compared to normal cells [3, 6-10]. Interestingly, in comparison to normal cells, cancer cells display higher uncoupled mitochondrial respiration [31]. Cancer cells upon treatment with metformin exhibit greater compensatory elevation in glycolysis than normal cells $[31,32]$, thus weighing the metabolic susceptibility of cancer cells. Therefore, inhibiting LDH or lactate generation/secretion suppresses cancer cell growth while normal cells are least affected as sufficient ATP can still be produced from OXPHOS because metformin is a weak complex I inhibitor. As OXPHOS activity is higher in normal cells as compared to the melanoma cells, metformin and oxamate/DCA combination is likely to have least adverse impact on respiration of normal cells.

Our study opens new avenues in targeting metabolism of cancer cells and can be further implicated in testing other clinically approved drugs known to inhibit glycolysis along with metformin. The present study suggests that any drug/inhibitor that blocks lactate generation can be used in combination with metformin for the better management and preventing tumor growth. For example, rapamycin, a clinically approved drug is shown to prevent lactate generation $[69,70]$. Similarly, it has been shown that inhibition of BRAF results in suppression of glycolysis [6, 7]. Therefore, rapamycin as well as BRAF inhibitors can be used along with metformin to improve therapeutic outcome with reduced side effects. Collectively, our results indicate that LDH or other mechanism which control lactate generation or secretion is critical for rapid melanoma progression under OXPHOS-compromised conditions, and this can be exploited as a suitable therapeutic target for controlling growth of glycolytic cancer cells. More extensive studies are needed to evaluate functionality of $\mathrm{LDH}$ and complex I in other cancer models, and subsequently their implication in cancer therapy in general.

\section{MATERIALS AND METHODS}

\section{Animal experiments}

Mice were procured from Experimental Animal Facility (EAF) at National Centre for Cell Science (NCCS), Pune, India. Hyperglycemia in mice was induced using STZ as previously described [71] with slight modifications. Briefly, male C57BL/6J and NOD/SCID mice were fasted for $6 \mathrm{~h}$ prior to intraperitoneal injection of STZ $(50 \mathrm{mg} / \mathrm{kg})$ in $0.01 \mathrm{M}$ citrate buffer $(\mathrm{pH} \mathrm{4.4)}$ ) for three consecutive days. Blood glucose measurement was performed by nipping the tail and applying blood on to a glucose analyzer (Accu-Chek Active, Roche, Germany). Mice having blood glucose value over $200 \mathrm{mg} / \mathrm{dl}$ were considered as hyperglycemic. Tumor was induced by injecting B16F10 $\left(2 \times 10^{5}\right)$ or A375 $\left(1 \times 10^{6}\right)$ cells in 100 $\mu 1$ sterile PBS subcutaneously at right flank of C57BL/6 J and NOD/SCID mice respectively. Tumor progression was monitored regularly by measuring its size with a digital caliper (Sigma, USA) following the appearance of palpable tumors. Oral administration of metformin on alternate days was initiated a week prior to tumor challenge in hyperglycemic mice. Otherwise metformin was given only after tumor reached to an optimum size and the treatment was continued till the completion of the experiment. At the end of the experiment, mice were sacrificed; tumors were excised and stored in either $-80^{\circ} \mathrm{C}$ or in $10 \%$ formalin solution for further studies. In another set of experiment, mice (C57BL/6J background, male) were randomly divided into 4 groups following the appearance of palpable tumor. To examine the outcome of metformin treatment in combination with LDH inhibitor oxamate, mice were given orally either metformin (200 $\mathrm{mg} / \mathrm{kg}$ ) or oxamate alone $(500 \mathrm{mg} / \mathrm{kg}$ ) or both together on every alternate day. Tumor progression was regularly monitored with a caliper. At the end of experiment, tumor, muscle and liver tissues were excised, weighed and stored in $-80^{\circ} \mathrm{C}$ for further analysis. All animal experiments have been performed as per the guidelines of the committee for the purpose of control and supervision of experiments on animals (CPCSEA), Government of India, and after obtaining permission of the Institute's Animal Ethics 
Committee (IAEC).

\section{Cell lines and culture conditions}

B16F10 murine melanoma, A375 and SKMel28 human melanoma cells were purchased from ATCC (VA, USA) and maintained in our in house repository. Noncancerous cells, AML12 (mouse hepatocytes), L6 (rat muscle cells) and MEF (mouse embryonic fibroblasts) were used in parallel along with cancer cells as a control. All the cells were grown in their respective medium containing either $1 \mathrm{mM}$ or $25 \mathrm{mM}$ glucose depending upon the experiments and supplemented with $10 \%$ heat inactivated fetal bovine serum (Hyclone, UT, USA), penicillin $(100 \mathrm{U} / \mathrm{ml})$ and streptomycin $100 \mu \mathrm{g} / \mathrm{ml}$ (Life Technologies, NY, USA), at $37^{\circ} \mathrm{C}$ in presence of $5 \% \mathrm{CO}_{2}$.

\section{Chemicals and reagents}

Metformin, phenformin, oligomycin, rotenone, decylubiquinone, streptozotocin (STZ), [3-(4, 5-dimethylthiazol-2-yl)-2, 5diphenylterazolium bromide] (MTT), NAD+, NADH, ATP, AMP, D-glucose, sodium oxamate, iodoacetate, 2-deoxy-D-glucose, dichloroacetate (DCA), Diaminobenzidine (DAB) and phloretin were purchased from Sigma (MO, USA). Antibodies for ChREBP (1:1000), GLUT1 (1:1000), LDHA (1:1000), Cyclin D1 (1:1000), PCNA (1:1000), CDK4 (1:1000), p21 (1:1000), E2F1 (1:1000) CD31 (1:100), PARP-1 (1:1000), Bcl-2 (1:1000), Bax (1:1000), $\beta$-tubulin (1:1000), GAPDH (1:1000), HSP60 (1:1000), and VEGF (1:50) were from Santa Cruz Biotechnology (CA, USA).

\section{Cell lysate preparation and immunoblotting}

Cells were washed thrice with phosphate buffered saline (PBS) and lysed in lysis buffer containing 50 $\mathrm{mM}$ Tris- $\mathrm{Cl}$ ( $\mathrm{pH}$ 7.5), $120 \mathrm{mM} \mathrm{NaCl}, 10 \mathrm{mM}$ sodium fluoride, $10 \mathrm{mM}$ sodium pyrophosphate, 2 mM EDTA, 1 $\mathrm{mM}$ sodium orthovanadate, $1 \mathrm{mM}$ phenylmethylsulfonyl fluoride, $1 \%$ NP-40 and protease inhibitor cocktail (Roche, Germany). Tumor Lysates were prepared by chopping tumor tissues into fine pieces, washed five times with $0.85 \%$ saline solution containing protease inhibitor cocktail and lysed in lysis buffer by homogenizing with a tissue homogenizer (Sigma, USA) followed by sonication. Lysates were clarified by centrifugation at 15,000 rpm for 30 minutes. Cell lysates were prepared under chilled conditions. Approximately, 50-100 $\mu \mathrm{g}$ of protein from whole cell lysates were resolved on $8-12 \%$ SDSpolyacrylamide gel which was subsequently transferred onto PVDF membrane (Millipore, Germany). The membrane was probed with desired primary antibodies followed by HRP-conjugated secondary antibodies.
Immunoblots were detected by luminal reagent (Santa Cruz Biotechnology). Whenever required, the blots were stripped by incubating the membrane at $50^{\circ} \mathrm{C}$ for $15 \mathrm{~min}$ in stripping buffer (62.5 mM Tris-Cl, pH 6.8, $100 \mathrm{mM}$ mercaptoethanol and $2 \%$ SDS) with intermittent shaking. Membranes were washed thoroughly with Tris buffered saline (TBS), and were reprobed with desired antibodies.

\section{Immunofluorescence or confocal microscopy}

Cells were plated in Labtek chambered slides (Nunc, USA) and allowed to grow for $24 \mathrm{~h}$. Treatment of metformin and other inhibitors were given for desired time periods and concentrations. Cells were washed with chilled sterile PBS and fixed with 3.7\% paraformaldehyde solution at room temperature for $10 \mathrm{~min}$. These were then permeabilized with $0.025 \%$ Triton X-100 in PBS for 10 min and subsequently blocked with 5\% BSA in PBS for $1 \mathrm{~h}$ at $37^{\circ} \mathrm{C}$. Cells were incubated with 1:100 dilutions of primary antibodies in the blocking solution for $2 \mathrm{~h}$ at room temperature and washed with TBST (TBS containing $0.05 \%$ Tween-20) at least five times before being incubated with appropriate labeled secondary antibodies (1:200) in blocking solution for further $1 \mathrm{~h}$ at room temperature. After five washes with TBST, samples were layered with mounting medium containing DAPI (Santa Cruz Biotechnology, USA). Slides were sealed, examined under a confocal laser scanning microscope (LSM510 Carl Zeiss, Germany) and images were captured. Images were subsequently processed by LSM image analysis software.

\section{Immunohistochemistry and histopathology}

Immunohistochemical and histopathology was performed according to the Malvi et al. [72]. Briefly, fine sections of tumor, and other organs were made with microtome fixed on glass slides and parafinized. For immunohistochemistry, slides were deparafinized in xylene solution twice for $10 \mathrm{~min}$, and subsequently washed thrice with $100 \%, 95 \%, 70 \%$ and $50 \%$ ethanol. Slides were again washed with distilled water followed by washing with PBS for 5 min. For antigen retrieval, slides were boiled in sodium citrate buffer $(0.01 \mathrm{M}, \mathrm{pH}$ 4.5 ) in microwave oven for $10 \mathrm{~min}$ and allowed to cool at room temperature for further $20 \mathrm{~min}$. BSA or normal goat serum $(2 \%)$ was used for blocking in humidified chamber or in cold box for $1 \mathrm{~h}$. Slides were probed with desired antibodies (1:100 dilution) in PBST (PBS containing $0.025 \%$ Tween-20) containing $0.01 \% \mathrm{BSA}$ for $2 \mathrm{~h}$ at room temperature or overnight at $4^{\circ} \mathrm{C}$. Slides were washed with PBST 4 times for $5 \mathrm{~min}$, and were probed with compatible HRP-conjugated secondary antibodies for $1 \mathrm{~h}$. These were again washed and stained with Diaminobenzidine (DAB) for $10 \mathrm{~min}$ followed by washing and counterstaining with hematoxylin. Slides were further washed with 
water, dehydrated with absolute alcohol followed by layering with mounting medium, and then analyzed for the expression of desired molecules. For histopathology, deparafinized slides were stained with hematoxylin and eosin, and microscopic analysis for cell density, cellular morphology, metastasis, cytotoxicity and necrosis was performed by pathologists in a blinded manner at KEM Hospital Pune, India.

\section{Cellular cytotoxicity and survival assay}

Approximately $5 \times 10^{3}(\mathrm{~B} 16 \mathrm{~F} 10)$ and $10 \times 10^{3}$ (A375 and SKMel28) cells were seeded in each well of 96 well tissue culture plates and allowed to adhere for $24 \mathrm{~h}$ at $37^{\circ} \mathrm{C}$. Cells were treated as per the experimental requirement and proliferation or viability was assessed by MTT assay. MTT $(50 \mu 1,1 \mathrm{mg} / \mathrm{ml}$ in DMEM without phenol red) was added to each well and incubated for $4 \mathrm{~h}$ at $37^{\circ} \mathrm{C}$. Formazan crystals were solubilized in 100 $\mu \mathrm{l}$ of isopropanol by incubating with shaking at room temperature for $5 \mathrm{~min}$. Absorbance was taken at $570 \mathrm{~nm}$ using $630 \mathrm{~nm}$ as reference filter. Untreated cells were considered as control (100\% cell survival).

\section{Detection of apoptosis by annexin V staining}

Cells were seeded at a density of approximately $3 \times 10^{5}$ cells in $35 \mathrm{~mm}$ plates and allowed to grow for $24 \mathrm{~h}$. Cells were treated with or without oxamate and DCA either alone or with metformin for $48 \mathrm{~h}$ or as the experimental requirement. Cells were harvested by trypsinization and processed for flow cytometry. Apoptosis was detected by dual staining of Annexin V and PI using apoptosis assay kit (BD Bioscience, USA) according to manufacturer's instructions.

\section{Cell cycle analysis}

Cells were seeded at a density of approximately 3 $\times 10^{5}$ cells in $35 \mathrm{~mm}$ plates and allowed to grow for 24 h. Cells were treated with or without metformin, oxamate and other glycolytic inhibitors alone or together as indicated for $48 \mathrm{~h}$ or as experimental requirement. Cells were harvested by trypsinization and processed for flow cytometry. Briefly, cells were washed with chilled PBS and fixed in $70 \%$ ethanol on ice for $30 \mathrm{~min}$. Following RNase $(200 \mu \mathrm{g} / \mathrm{ml})$ treatment for $30 \mathrm{~min}$ at $37^{\circ} \mathrm{C}, 50 \mu \mathrm{g} /$ $\mathrm{ml}$ PI was added to cell pellet and incubated in dark for 30 min on ice. The fluorescence of PI was recorded through a $585 \mathrm{~nm}$ filter in a flow cytometer (FACS Calibur, Becton Dickinson, California, USA). Data were analyzed using Cell Quest Pro software for 10,000 cells.

\section{Long term cell survival assay}

Cells $\left(5 \times 10^{2}\right)$ were plated in 12 well plates for 24 h. Cells were treated without or with $25 \mathrm{mM}$ or $50 \mathrm{mM}$ oxamate and 10 or $20 \mathrm{mM}$ DCA along with metformin and continued for further $48 \mathrm{~h}$. Subsequently, medium was replaced with fresh drug-free medium. Plates were incubated for an additional $10-15$ days at $37^{\circ} \mathrm{C}$ in $\mathrm{CO}_{2}$ incubator with medium change on every 2-3 days. Cells were then fixed (3\% paraformaldehyde and $0.02 \%$ glutaraldehyde in PBS) and stained with $0.05 \%$ crystal violet.

\section{Glucose utilization assay}

Cells $\left(3 \times 10^{5}\right)$ were cultured in DMEM containing $25 \mathrm{mM}$ glucose. After $24 \mathrm{~h}$, medium was replaced with respective medium containing increasing concentration of metformin ( $0.1 \mathrm{mM}, 0.5 \mathrm{mM}, 1 \mathrm{mM}$, and $2 \mathrm{mM})$ or rotenone for $24 \mathrm{~h}$ and residual glucose present in the spent medium was monitored using GOD-POD based glucose assay kit (Spinreact, Spain) according to manufacturer's instructions. For measuring glucose utilization in the presence glycolytic inhibitors, cells were treated with $50 \mathrm{mM}$ oxamate, $100 \mu \mathrm{M}$ phloretin, and $20 \mathrm{mM}$ DCA, either alone or together with $2 \mathrm{mM}$ metformin or 100 $\mu \mathrm{M}$ phenformin. Consumed glucose was estimated by subtracting the remaining glucose in the medium from the initial concentration in control medium $(450 \mathrm{mg} / \mathrm{dl})$. The experiments were performed at least in triplicate and values were normalized to total number of cells.

\section{Lactate estimation assay}

Lactate concentration in spent medium collected from the cells treated with or without metformin, oxamate and other glycolytic inhibitors, was determined using commercially available lactate estimation kit (Spinreact, Spain) as per the manufacturer's instructions. Briefly, culture medium or serum was diluted in $0.9 \%$ saline up to 10 times and $10 \mu \mathrm{l}$ of sample was added to each well of 96 well ELISA plate. $150 \mu \mathrm{l}$ of reagent provided with kit was added to each sample containing wells keeping unspent medium and reagent alone as blank and absorbance was recorded at $405 \mathrm{~nm}$ using a spectrophotometer (ThermoScientific, USA). Experiments were done at least in triplicate and the final values were normalized with total number of cells.

\section{siRNA transfection}

Specific siRNA against LDHA was purchased from Santa Cruz Biotechnology (USA). Transfection was done using Lipofectamine 2000 (Life Technologies, USA) 
according to manufacturer's instructions. In brief, cells were plated at approximately $60 \%$ confluency. Next day, medium was replaced with OptiMEM (Life Technologies, USA) and kept for $3 \mathrm{~h}$. Desired siRNAs were dissolved in buffers provided along with them. Lipofectamine 2000 and siRNA were diluted separately in OptiMEM and incubated for $5 \mathrm{~min}$. Thereafter, diluted reagents were mixed and further incubated for $30 \mathrm{~min}$ at room temperature. The resultant precipitate was left on the cells for $6 \mathrm{~h}$, after which fresh DMEM supplemented with 10\% FBS was added and incubated for further 24-36 h. Transfection efficiency was assessed by simultaneously transfecting pEGFPN1 plasmid. Immunoblotting was performed to ensure inhibition of respective gene expression.

\section{Preparation of mitochondria rich fraction from cells and tissues}

Mitochondria rich fraction was prepared from cultured cells and tumors or normal tissues as previously reported [73]. Briefly, cells $\left(1 \times 10^{6}\right)$ were plated in 10 $\mathrm{cm}$ plate and were trypsinized following treatment with the desired inhibitors for $24 \mathrm{~h}$. Cell suspension was subjected to three cycles of freeze-thawing in hypotonic buffer (20 mM potassium phosphate). This suspension was centrifuged at 50,000 rpm for $1 \mathrm{~h}$ to obtain supernatant rich in mitochondria. Similarly, to isolate mitochondria from tissues, frozen tissues were chopped into fine pieces and homogenized in homogenization buffer $(0.5 \mathrm{M}$ Tris buffer $\mathrm{pH} 7.5,100 \mathrm{mM}$ EGTA, and $250 \mathrm{mM}$ sucrose), followed by cyclic freeze-thaw procedure and centrifuged at 50,000 rpm for $1 \mathrm{~h}$. Supernatant was collected as mitochondrial fraction and used for the determination of mitochondrial function and OXPHOS enzyme activity.

\section{Enzyme assays}

Cells were homogenized in hypotonic $(20 \mathrm{mM})$ potassium phosphate buffer ( $\mathrm{pH}$ 7.5) containing protease inhibitor cocktail (Roche, Germany), vortexed and lysed by three cycles of freeze and thaw procedure. For preparing extract from tissues, tumor samples were chopped into fine pieces and homogenized in homogenization buffer $(0.1 \mathrm{M}$ Tris, $0.1 \mathrm{M} \mathrm{KCl}, 350 \mathrm{mM}$ EDTA and $1 \mathrm{M}$ sucrose, $\mathrm{pH}$ 7.5) using tissue homogenizer. Homogenates were clarified by centrifuging at $10,000 \mathrm{rpm}$ for $10 \mathrm{~min}$ at $4^{\circ} \mathrm{C}$ and kept on ice until the assays are performed.

LDH activity assay: Lactate dehydrogenase activity in cell lysates or tumor extract and serum was determined using LDH activity assay kit (Spinreact, Spain) according to manufactures instructions.

Complex I activity assay: Mitochondrial OXPHOS complex I enzyme assay was performed as described elsewhere [73]. Briefly, mitochondrial rich fraction of cell or tissue homogenate (20-50 $\mu \mathrm{g}$ of protein from tissue homogenate or $10-20 \mu \mathrm{g}$ of mitochondrial rich fraction) was added to $700 \mu \mathrm{l}$ of distilled water taken in a $1 \mathrm{ml}$ cuvette, followed by addition of $100 \mu \mathrm{l}$ potassium phosphate buffer $(0.5 \mathrm{M}, \mathrm{pH} 7.5), 60 \mu \mathrm{l}$ of fatty acid-free BSA $(50 \mathrm{mg} / \mathrm{ml}), 30 \mu \mathrm{l}$ of $\mathrm{KCN}(10 \mathrm{mM})$ and $10 \mu \mathrm{L}$ of NADH $(10 \mathrm{mM})$. Final volume was adjusted to $994 \mu \mathrm{l}$ using distilled water, mixed by inverting the cuvettes and the baseline reading was acquired at $340 \mathrm{~nm}$ for $2 \mathrm{~min}$. Reaction was started by adding $6 \mu$ of decylubiquinone (10 mM, Sigma, USA) mixed properly by inverting the cuvettes. Decrease in the absorbance at $340 \mathrm{~nm}$ was followed for $10 \mathrm{~min}$. Similar procedure was followed for the calculation of complex I activity in presence 2 $\mathrm{mM}$ metformin and $100 \mu \mathrm{M}$ phenformin. Rotenone (10 $\mu \mathrm{M})$ was used as a positive control. Final values were normalized with total cellular protein content.

\section{Total cellular ATP measurement}

ATP level was measured by using commercially available ATP bioluminescence kit (Roche, Germany) according to manufacturer's instructions. Briefly, cells were grown in the presence of indicated drugs. Cells were harvested and lysed in $100 \mathrm{mM}$ Tris-EDTA buffer containing $0.01 \% \mathrm{NP}-40$ and boiled for $1 \mathrm{~min}$ followed by thee freeze-thaw cycle. Luminescence was recorded for blank as well as for samples. For measuring ATP generated exclusively through OXPHOS and glycolysis, cells were treated with oligomycin $(10 \mu \mathrm{M})$ and oxamate or DCA respectively with or without metformin. Experiments were done in triplicate and repeated at least once, and final values were normalized with total protein contents.

\section{Statistics}

Statistical analysis was performed using Sigma Plot 12.0 (Systat Software Inc., CA, USA). Most of the experiments were repeated at least once with minimum in triplicate unless otherwise mentioned. Data was represented as mean $\pm \mathrm{SD}$ except for the indicated experiments. Wherever required, either paired or unpaired, two tailed student $t$-test was employed in the experiments assuming unequal variance unless otherwise mentioned, to calculate $\mathrm{p}$-value. The values $* p<0.05, * * p<0.01, * * * p$ $<0.001$ denote significant differences between the groups $(n>3$ at the least).

\section{ACKNOWLEDGMENTS}

The authors thank Dr. S.C. Mande, Director, NCCS, Pune, India, and Dr. G.C. Mishra, former Director, NCCS, Pune, India for being very supportive and giving all the encouragement to carry out this work. We thank Dr. Benoit violet (INSERM, France) for providing MEFs, Dr. Mahesh J Kulkarni (National Chemical Laboratory, 
India) for L6 cells and Dr. Rakesh K Tyagi (Jawaharlal Nehru University, India) for providing AML12 cells. We also thank Dr. Vijayakumar MV for helping in animal experiments and for critical reading of manuscript. $\mathrm{BC}$ and NM thank Council of Scientific and Industrial Research (CSIR) India; PM and SVS thank University Grant Commission (UGC), India for providing fellowship. The support from other lab members and colleagues at NCCS as well as staff members from Experimental Animal Facility, FACS, Confocal and mass spectrometry facility is duly acknowledged.

\section{FINANCIAL SUPPORTS}

This work was supported by intramural grant from NCCS funded by Department of Biotechnology, Government of India.

\section{CONFLICTS OF INTEREST}

Authors declare that they do not have any potential conflicts of interest

\section{NOTE}

This work was carried out in partial fulfillment of a Ph.D. thesis (of B.C.) to be submitted to Savitribai Phule Pune University, Pune, India.

\section{REFERENCES}

1. Gray-Schopfer V, Wellbrock C, Marais R. Melanoma biology and new targeted therapy. Nature. 2007; 445:851857.

2. Demierre MF. Epidemiology and prevention of cutaneous melanoma. Curr Treat Options Oncol. 2006; 7:181-186.

3. Hersey P, Watts RN, Zhang XD, Hackett J. Metabolic approaches to treatment of melanoma. Clin Cancer Res. 2009; 15:6490-6494.

4. Warburg O. On respiratory impairment in cancer cells. Science. 1956; 124:269-270.

5. Vander Heiden MG, Cantley LC, Thompson CB. Understanding the Warburg effect: the metabolic requirements of cell proliferation. Science. 2009; 324:10291033.

6. Hall A, Meyle KD, Lange MK, Klima M, Sanderhoff M, Dahl C, Abildgaard C, Thorup K, Moghimi SM, Jensen PB, Bartek J, Guldberg P, Christensen C. Dysfunctional oxidative phosphorylation makes malignant melanoma cells addicted to glycolysis driven by the (V600E)BRAF oncogene. Oncotarget. 2013; 4:584-599.

7. Haq R, Shoag J, Andreu-Perez P, Yokoyama S, Edelman H, Rowe GC, Frederick DT, Hurley AD, Nellore A, Kung AL, Wargo JA, Song JS, Fisher DE, et al. Oncogenic BRAF regulates oxidative metabolism via PGC1 $\alpha$ and MITF. Cancer Cell. 2013; 23:302-315.

8. Weide B, Elsässer M, Büttner P, Pflugfelder A, Leiter U, Eigentler TK, Bauer J, Witte M, Meier F, Garbe C. Serum markers lactate dehydrogenase and S100B predict independently disease outcome in melanoma patients with distant metastasis. Br J Cancer. 2012; 107:422-428.

9. Deichmann M, Benner A, Bock M, Jäckel A, Uhl K, Waldmann V, Näher H. S100-Beta, melanoma-inhibiting activity, and lactate dehydrogenase discriminate progressive from nonprogressive American Joint Committee on Cancer stage IV melanoma. J Clin Oncol. 1999; 17:1891-1896.

10. Giatromanolaki A, Sivridis E, Gatter KC, Turley H, Harris AL, Koukourakis MI; Tumor and Angiogenesis Research Group. Lactate dehydrogenase 5 (LDH-5) expression in endometrial cancer relates to the activated VEGF/ VEGFR2(KDR) pathway and prognosis. Gynecol Oncol. 2006; 103:912-918.

11. Koukourakis MI, Giatromanolaki A, Sivridis E. Lactate dehydrogenase isoenzymes 1 and 5: differential expression by neoplastic and stromal cells in non-small cell lung cancer and other epithelial malignant tumors. Tumour Biol. 2003; 24:199-202.

12. Fantin VR, St-Pierre J, Leder P. Attenuation of LDH-A expression uncovers a link between glycolysis, mitochondrial physiology, and tumor maintenance. Cancer Cell. 2006; 9:425-434.

13. Brandon M, Baldi $\mathrm{P}$, Wallace DC. Mitochondrial mutations in cancer. Oncogene. 2006; 25:4647-4662.

14. Ishikawa $\mathrm{K}$, Takenaga $\mathrm{K}$, Akimoto M, Koshikawa N, Yamaguchi A, Imanishi H, Nakada K, Honma Y, Hayashi J. ROS-generating mitochondrial DNA mutations can regulate tumor cell metastasis. Science. 2008; 320:661-664.

15. Wallace DC. A mitochondrial paradigm of metabolic and degenerative diseases, aging, and cancer: a dawn for evolutionary medicine. Annu Rev Genet. 2005; 39:359-407.

16. Santidrian AF, Matsuno-Yagi A, Ritland M, Seo BB, LeBoeuf SE, Gay LJ, Yagi T, Felding-Habermann B. Mitochondrial complex I activity and NAD+/NADH balance regulate breast cancer progression. J Clin Invest. 2013; 123:1068-1081.

17. He X, Zhou A, Lu H, Chen Y, Huang G, Yue X, Zhao P, $\mathrm{Wu}$ Y. Suppression of mitochondrial complex I influences cell metastatic properties. PLoS One. 2013; 8:e61677.

18. Sharma LK, Fang H, Liu J, Vartak R, Deng J, Bai Y. Mitochondrial respiratory complex I dysfunction promotes tumorigenesis through ROS alteration and AKT activation. Hum Mol Genet. 2011; 20:4605-4616.

19. Gopal YN, Rizos H, Chen G, Deng W, Frederick DT, Cooper ZA, Scolyer RA, Pupo G, Komurov K, Sehgal V, Zhang J, Patel L, Pereira CG et al. Inhibition of mTORC1/2 overcomes resistance to MAPK pathway inhibitors mediated by $\mathrm{PGC} 1 \alpha$ and oxidative phosphorylation in melanoma. Cancer Res. 2014; 74:7037-7047. 
20. Barbi de Moura M, Vincent G, Fayewicz SL, Bateman NW, Hood BL, Sun M, Suhan J, Duensing S, Yin Y, Sander C, Kirkwood JM, Becker D, Conrads TP, et al. Mitochondrial respiration--an important therapeutic target in melanoma. PLoS One. 2012; 7:e40690.

21. Blackman RK, Cheung-Ong K, Gebbia M, Proia DA, He S, Kepros J, Jonneaux A, Marchetti P, Kluza J, Rao PE, Wada Y, Giaever G, Nislow C. Mitochondrial electron transport is the cellular target of the oncology drug elesclomol. PLoS One. 2012; 7:e29798.

22. Filipp FV, Scott DA, Ronai ZA, Osterman AL, Smith JW. Reverse TCA cycle flux through isocitrate dehydrogenases 1 and 2 is required for lipogenesis in hypoxic melanoma cells. Pigment Cell Melanoma Res. 2012; 25:375-383.

23. Lim JH, Luo C, Vazquez F, Puigserver P. Targeting mitochondrial oxidative metabolism in melanoma causes metabolic compensation through glucose and glutamine utilization. Cancer Res. 2014; 74:3535-3545.

24. Evans JM, Donnelly LA, Emslie-Smith AM, Alessi DR, Morris $\mathrm{AD}$. Metformin and reduced risk of cancer in diabetic patients. British Medical Journal. 2005; 330:13041305.

25. Decensi A, Puntoni M, Goodwin P, Cazzaniga M, Gennari A, Bonanni B, Gandini S. Metformin and cancer risk in diabetic patients: a systematic review and meta-analysis. Cancer Prev Res (Phila). 2010; 3:1451-1461.

26. Kirpichnikov D, McFarlane SI, Sowers JR. Metformin: an update. Ann Intern Med. 2002; 137:25-33.

27. Pollak MN. Investigating metformin for cancer prevention and treatment: the end of the beginning. Cancer Discov. 2012; 2:778-790.

28. El-Mir MY, Nogueira V, Fontaine E, Averet N, Rigoulet M, Leverve X. Dimethylbiguanide inhibits cell respiration via an indirect effect targeted on the respiratory chain complex I. J Biol Chem. 2000; 275:223-228.

29. Owen MR, Doran E, Halestrap AP. Evidence that metformin exerts its anti-diabetic effects through inhibition of complex 1 of the mitochondrial respiratory chain. Biochem J. 2000; 348:607-614.

30. Wheaton WW, Weinberg SE, Hamanaka RB, Soberanes S, Sullivan LB, Anso E, Glasauer A, Dufour E, Mutlu GM, Budigner GS, Chandel NS. Metformin inhibits mitochondrial complex I of cancer cells to reduce tumorigenesis. Elife. 2014; 3:e02242.

31. Andrzejewski S, Gravel SP, Pollak M, St-Pierre J. Metformin directly acts on mitochondria to alter cellular bioenergetics. Cancer Metab. 2014; 2:12.

32. Sesen J, Dahan P, Scotland SJ, Saland E, Dang VT, Lemarié A, Tyler BM, Brem H, Toulas C, Cohen-Jonathan Moyal E, Sarry JE, Skuli N. Metformin inhibits growth of human glioblastoma cells and enhances therapeutic response. PLoS One. 2015; 10:e0123721.

33. Ben Sahra I, Laurent K, Loubat A, Giorgetti-Peraldi S, Colosetti P, Auberger P, Tanti JF, Le Marchand-Brustel
Y, Bost F. The antidiabetic drug metformin exerts an antitumoral effect in vitro and in vivo through a decrease of cyclin D1 level. Oncogene. 2008; 27:3576-3586.

34. Zakikhani M, Dowling R, Fantus IG, Sonenberg N, Pollak M. Metformin is an AMP kinase dependent growth inhibitor for breast cancer cells. Cancer Res. 2006; 66:10269-10273.

35. Martin MJ, Hayward R, Viros A, Marais R. Metformin accelerates the growth of BRAF V600E-driven melanoma by upregulating VEGF-A. Cancer Discov. 2012, 2:344-355.

36. Tomic T, Botton T, Cerezo M, Robert G, Luciano F, Puissant A, Gounon P, Allegra M, Bertolotto C, Bereder JM, Tartare-Deckert S, Bahadoran P, Auberger P, et al. Metformin inhibits melanoma development through autophagy and apoptosis mechanisms. Cell Death Dis. 2011; 2:e199.

37. Cerezo M, Tichet M, Abbe P, Ohanna M, Lehraiki A, Rouaud F, Allegra M, Giacchero D, Bahadoran P, Bertolotto C, Tartare-Deckert S, Ballotti R, Rocchi S. Metformin blocks melanoma invasion and metastasis development in AMPK/p53-dependent manner. Mol Cancer Ther. 2013; 12:1605-1615.

38. Yuan P, Ito K, Perez-Lorenzo R, Del Guzzo C, Lee JH, Shen $\mathrm{CH}$, Bosenberg MW, McMahon M, Cantley LC, Zheng B. Phenformin enhances the therapeutic benefit of BRAF(V600E) inhibition in melanoma. Proc Natl Acad Sci USA. 2013; 110:18226-18231.

39. Cannino G, El-Khoury R, Pirinen M, Hutz B, Rustin P, Jacobs HT, Dufour E. Glucose modulates respiratory complex I activity in response to acute mitochondrial dysfunction. J Biol Chem. 2012; 287:38729-38740.

40. Xu RH, PelicanoH, Zhou Y, CarewJS, Feng L, Bhalla KN, Keating MJ, Huang P. Inhibition of glycolysis in cancer cells: a novel strategy to overcome drug resistance associated with mitochondrial respiratory defect and hypoxia. Cancer Res. 2005; 65:613-621.

41. Pan JG, Mak TW. Metabolic targeting as an anticancer strategy: dawn of a new era? Sci STKE. 2007; 2007:pe14.

42. Dalva-Aydemir S, Bajpai R, Martinez M, Adekola KU, Kandela I, Wei C, Singhal S, Koblinski JE, Raje NS, Rosen ST, Shanmugam M. Targeting the Metabolic Plasticity of Multiple Myeloma with FDA-Approved Ritonavir and Metformin. Clin Cancer Res. 2015; 21:1161-1171.

43. Menendez JA, Oliveras-Ferraros C, Cufí S, CorominasFaja B, Joven J, Martin-Castillo B, Vazquez-Martin A. Metformin is synthetically lethal with glucose withdrawal in cancer cells. Cell Cycle. 2012; 11:2782-2792.

44. Calabrese C, Iommarini L, Kurelac I, Calvaruso MA, Capristo M, Lollini PL, Nanni P, Bergamini C, Nicoletti G, Giovanni CD, Ghelli A, Giorgio V, Caratozzolo MF, et al. Respiratory complex I is essential to induce a Warburg profile in mitochondria-defective tumor cells. Cancer Metab. 2013; 1:11.

45. Semenza GL. Tumor metabolism: cancer cells give and take lactate. J Clin Invest. 2008; 118:3835-3837. 
46. Sonveaux P, Vegran F, Schroeder T, Wergin MC, Verrax J, Rabbani ZN, De Saedeleer CJ, Kennedy KM, Diepart C, Jordan BF, Kelley MJ, Bernard Gallez B, Wahl ML, et al. Targeting lactate-fueled respiration selectively kills hypoxic tumor cells in mice. J Clin Invest. 2008; 118:3930-3942.

47. Phoenix KN, Vumbaca F, Claffey KP. Therapeutic metformin/AMPK activation promotes the angiogenic phenotype in the ERalpha negative MDA-MB-435 breast cancer model. Breast Cancer Res Treat. 2009; 113:101-111.

48. Végran F, Boidot R, Michiels C, Sonveaux P, Feron O. Lactate influx through the endothelial cell monocarboxylate transporter MCT1 supports an NF- $\mathrm{KB} / \mathrm{IL}-8$ pathway that drives tumor angiogenesis. Cancer Res. 2011; 71:25502560.

49. Sonveaux P, Copetti T, De Saedeleer CJ, Vegran F, Verrax J, Kennedy KM, Moon EJ, Dhup S, Danhier P, Frérart F, Gallez B, Ribeiro A, Michiels C, et al. Targeting the lactate transporter MCT1 in endothelial cells inhibits lactateinduced HIF-1 activation and tumor angiogenesis. PLoS ONE. 2012; 7:e33418.

50. Wu M, Seto E, Zhang J. E2F1 enhances glycolysis through suppressing Sirt6 transcription in cancer cells. Oncotarget. 2015; 6:11252-11263.

51. Hernlund E, Strandberg Ihrlund L, Khan O, Ates YO, Linder S, Panaretakis T, Shoshan MC. Potentiation of chemotherapeutic drugs by energy metabolism inhibitors 2-deoxyglucose and etomoxir. Int J Cancer. 2008; 123:476483.

52. Wong JY, Huggins GS, Debidda M, Munshi NC, De Vivo I. Dichloroacetate induces apoptosis in endometrial cancer cells. Gynecol Oncol. 2008; 109:402.

53. Michelakis ED, Webster L, Mackey JR. Dichloroacetate (DCA) as a potential metabolic-target in therapy for cancer. Br J Cancer. 2008; 99:989-994.

54. Walenta S, Mueller-Kliese WF. Lactate: mirror and motor of tumor malignancy. Semin Radiat Oncol. 2004; 14:267274.

55. Doherty JR, Cleveland JL. Targeting lactate metabolism for cancer therapeutics. J Clin Invest. 2013; 123:3685-3692.

56. Le A, Cooper CR, Gouw AM, Dinavahi R, Maitra A, Deck LM, Royer RE, Vander Jagt DL, Semenza GL, Dang CV. Inhibition of lactate dehydrogenase A induces oxidative stress and inhibits tumor progression. Proc Natl Acad Sci USA. 2010; 107:2037-2042.

57. Zhao YH, Zhou M, Liu H, Ding Y, Khong HT, Yu D, Fodstad O, Tan M. Upregulation of lactate dehydrogenase A by ErbB2 through heat shock factor 1 promotes breast cancer cell glycolysis and growth. Oncogene. 2009; 28:3689-3701.

58. Kluza J, Corazao-Rozas P, Touil Y, Jendoubi M, Maire C, Guerreschi P, Jonneaux A, Ballot C, Balayssac S, Valable S, Corroyer-Dulmont A, Bernaudin M, Malet-Martino M, et al. Inactivation of the HIF- $1 \alpha / \mathrm{PDK} 3$ signaling axis drives melanoma toward mitochondrial oxidative metabolism and potentiates the therapeutic activity of pro-oxidants. Cancer Res. 2012; 72:5035-5047.

59. Parmenter TJ, Kleinschmidt M, Kinross KM, Bond ST, Li J, Kaadige MR, Rao A, Sheppard KE, Hugo W, Pupo GM, Pearson RB, McGee SL, Long GV, et al. Response of BRAF-mutant melanoma to BRAF inhibition is mediated by a network of transcriptional regulators of glycolysis. Cancer Discov. 2014; 4:423-433.

60. Miskimins WK, Ahn HJ, Kim JY, Ryu S, Jung YS, Choi JY. Synergistic anti-cancer effect of phenformin and oxamate. PLoS One. 2014; 9:e85576.

61. Jin S, DiPaola RS, Mathew R, White E. Metabolic catastrophe as a means to cancer cell death. J Cell Sci. 2007; 120:379-383.

62. McLornan DP, List A, Mufti GJ. Applying synthetic lethality for the selective targeting of cancer. N Engl J Med. 2014; 371:1725-1735.

63. Kaelin WG Jr. The concept of synthetic lethality in the context of anticancer therapy. Nat Rev Cancer. 2005; 5:689698.

64. Iaquinta PJ, Lees JA. Life and death decisions by the E2F transcription factors. Curr Opin Cell Biol. 2007; 19:649657.

65. Houben R, Hesbacher S, Schmid CP, Kauczok CS, Flohr U, Haferkamp S, Müller CS, Schrama D, Wischhusen J, Becker JC. High-level expression of wild-type p53 in melanoma cells is frequently associated with inactivity in p53 reporter gene assays. PLoS One. 2011; 6:e22096.

66. Avery-Kiejda KA, Bowden NA, Croft AJ, Scurr LL, Kairupan CF, Ashton KA, Talseth-Palmer BA, Rizos H, Zhang XD, Scott RJ, Hersey P. P53 in human melanoma fails to regulate target genes associated with apoptosis and the cell cycle and may contribute to proliferation. BMC Cancer. 2011; 11:203.

67. Lu M, Breyssens H, Salter V, Zhong S, Hu Y, Baer C, Ratnayaka I, Sullivan A, Brown NR, Endicott J, Knapp S, Kessler BM, Middleton MR, et al. Restoring p53 function in human melanoma cells by inhibiting MDM2 and cyclin B1/CDK1-phosphorylated nuclear iASPP. Cancer Cell. 2013; 23:618-633.

68. Pandey V, Vijayakumar MV, Ajay AK, Malvi P, Bhat MK. Diet-induced obesity increases melanoma progression: involvement of Cav-1 and FASN. Int J Cancer. 2012; 130:497-508.

69. Leontieva OV, Blagosklonny MV. M(o)TOR of pseudohypoxic state in aging: rapamycin to the rescue. Cell Cycle. 2014; 13:509-515.

70. Leontieva OV, Blagosklonny MV. Yeast-like chronological senescence in mammalian cells: phenomenon, mechanism and pharmacological suppression. Aging (Albany NY). 2011; 3:1078-1091.

71. Vijayakumar MV, Singh S, Chhipa RR, Bhat MK. The hypoglycaemic activity of fenugreek seed extract is mediated through the stimulation of an insulin signalling 
pathway. Br J Pharmacol. 2005; 146:41-48.

72. Malvi P, Chaube B, Pandey V, Vijayakumar MV, Boreddy PR, Mohammad N, Singh SV, Bhat MK. Obesity induced rapid melanoma progression is reversed by orlistat treatment and dietary intervention: role of adipokines. Mol Oncol. 2015; 9:689-703.

73. Spinazzi M, Casarin A, Pertegato V, Salviati L, Angelini C. Assessment of mitochondrial respiratory chain enzymatic activities on tissues and cultured cells. Nat Protoc. 2012; 7 : 1235-1246. 